\title{
Polymer membrane-based ion-, gas- and bio-selective potentiometric sensors
}

\author{
Hyoung-Sik Yim, Christopher E. Kibbey, Shu-Ching Ma, Dennis M. Kliza, \\ Dong Liu, Sung-Bae Park, Cecilia Espadas Torre \& Mark E. Meyerhoff*
}

Department of Chemistry, University of Michigan, Ann Arbor, MI 48109, USA

(Received 1 May 1992; revised version received and accepted 26 August 1992)

\begin{abstract}
Recent progress in the design of new polymer membrane-based potentiometric ion-, gas- and bio-selective electrodes in chemistry laboratories at the University of Michigan (Ann Arbor) is reviewed. Emphasis is placed on describing the performance of devices for measuring anions (e.g., salicylate, thiocyanate, chloride and heparin) and gases (e.g., ammonia, carbon dioxide and oxygen) in biological samples, both in vitro and in vivo. Beyond direct measurement of key ions and gases in complex matrices, some of the new membrane electrode systems reported can serve as base transducers for the development of biosensors containing integrated biological reagents, including enzymes and antibodies. New approaches for mass fabricating solid-state ion and biosensor devices as well as future directions for research in the entire field of polymer membrane sensors are also described.
\end{abstract}

Keywords: anion, biosensor, ion-selective electrode, membrane, potentiometric.

\section{INTRODUCTION}

The development of electrochemical sensors for direct monitoring of key ions, gases and biochemicals in complex biological samples is a rapidly growing avenue of research. Although a wide variety of highly sophisticated transducer/ chemistry/biochemistry detection schemes have been proposed over the past 30 years, only a handful of sensor designs have displayed suitable analytical performance (i.e., selectivity, reproducibility etc.) for routine use in 'real world' bioanalytical measurements. Among the most successful sensors are cation-selective electrodes based on polymer membranes (Oesch et al., 1986;

*To whom correspondence should be addressed.
Byrne, 1988; Meyerhoff, 1990; Lewenstam et al., 1991). Indeed, instruments incorporating such potentiometric devices have completely replaced classical atomic spectroscopic techniques in clinical chemistry laboratories for measurement of electrolyte cations $\left(\mathrm{K}^{+}, \mathrm{Na}^{+}, \mathrm{Ca}^{++}, \mathrm{Li}^{+}\right)$in physiological samples, including undiluted whole blood (Meyerhoff, 1990). Interest in using polymeric ion-selective membranes as transducers in the design of various types of bioanalytical sensors, ranging from simple ion sensors to more complex enzyme- and antibodybased probes, arises from the high selectivity, rapid response times and ease of fabrication associated with these devices.

Polymer membrane-type ion-selective electrodes (ISEs) are in fact relatively simple 
electrochemical probes. There are two common arrangements used to prepare functional sensors: (a) the conventional design with internal reference electrolyte; and (b) the so-called 'solid-contact' configuration in which the polymer membrane is in direct contact with an electron conductor (i.e., no internal electrolyte). The membrane/film is typically made of plasticized poly(vinylchloride) (PVC) or unplasticized silicone rubber, although a large number of other polymer matrices may also be used (see Section 4.1 below). In either the conventional or the solid-contact configuration, selectivity for one ion over another is dictated by the chemical components doped into the organic polymer film. It is the selective extraction of ions at the membrane/sample interface that yields the measured phase boundary electrical potential between the surface of the membrane and the solution. Chemical species doped into the membranes to achieve the desired selectivity include electrically charged (e.g., dissociated ionexchangers or charged carriers) and uncharged carriers (e.g., neutral macrocyclic antibiotics, crown ethers, synthetic ionophores etc.). These compounds tend to be rather hydrophobic molecules that remain within the organic membrane phase even upon repeated exposure to aqueous samples. Typically, $1-5 \mathrm{wt} \%$ of ionophore or carrier doped within the membrane phase is required to achieve optimal potentiometric response. A modest concentration of lipophilic counter ion sites is also often added to the polymer film to reduce electrical resistance and improve ion selectivity (Morf, 1981; Meier et al., 1984; Ammann et al., 1985).

In practice, the measured potential of a working polymer membrane electrode is measured vs. a suitable reference electrode (e.g., $\mathrm{Ag} / \mathrm{AgCl}$ or $\mathrm{Hg} / \mathrm{Hg}_{2} \mathrm{Cl}_{2}$ ). The resulting cell potential (in volts) can be expressed by the wellknown Nicolsky equation:

$$
E_{\mathrm{cell}}=K+\frac{0 \cdot 059}{Z_{i}} \log \left(a_{i}+\sum_{j} k_{i, j}^{\text {pot }} a_{j}^{Z, / Z}\right)
$$

where $K$ is the cell constant (including reference electrode potentials), $a_{\imath}$ and $a_{j}$ are the activities of the analyte and potential interferent ions, respectively, $Z_{i}$ and $Z_{j}$ are the charges on these ions, and $k_{i, j}^{\text {pot }}$ is the potentiometric selectivity coefficient of the membrane electrode. For the cell potential to be relatively independent of interferent ion levels, $k_{i, j}^{\text {pot }}$ values should be as small as possible, although the precise values required for accurate detection of the analyte ion (i) will depend on its concentration and that of various interferent ions within a given sample.

While most ISEs cannot be classified as true biosensors (i.e., devices that utilize a biological recognition element), it is important to recognize that certain polymer membrane-based ion sensors (e.g., potassium- and ammoniumselective electrodes based on the antibiotics valinomycin and nonactin, respectively) are in fact biosensors, since selective ionic recognition is achieved using an immobilized form of the antibiotic ionophore reagents obtained from living organisms (Stefanac \& Simon, 1966). Thus, in some cases, polymer membrane electrodes fall into the unique category of being both biosensors themselves, and attractive transducers onto which additional biological reagents can be immobilized for biosensing purposes.

As stated above, there has already been considerable success in the development of polymer membrane-type electrodes for selective detection of cations. Thus the primary focus of our research over the past decade has been to expand the range of species that can be sensed by these types of electrochemical probe. Toward this goal, we have focused our efforts on studying new membrane chemistries and sensor arrangements/ systems that may ultimately be useful in detecting specific anions, gases and biomolecules in complex biological samples. In this review we provide appropriate background relevant to these efforts, give a summary of recent results from our laboratory, and touch upon some future directions for advances in this area.

\section{ANION-SELECTIVE ELECTRODES}

\subsection{Background}

A number of potentiometric anion-selective sensors based on solid-state inorganic crystalline membranes have been available commercially for some time. Aside from the fluoride-selective electrode based on an $\mathrm{LaF}_{3}$ crystal, many of these anion electrodes employ mixed precipitate membranes of $\mathrm{AgS} / \mathrm{AgX}$, where $X$ is the target anion (e.g., $\mathrm{Cl}^{-}, \mathrm{Br}^{-}, \mathrm{I}^{-}, \mathrm{SCN}^{-}$etc.). While quite useful for direct anion measurements in certain types of industrial and water samples, detection 
of given anions in complex biological fluids is problematic. In practice, the presence of proteins can cause significant interference due to the complexation of silver ions by thiol groups of the cysteine residues present in such macromolecules (D'Orazio \& Rechnitz, 1977). This has severely limited the application of existing anion-selective solid-state electrodes for measurements in biological samples.

The polymer membrane-based sensor designs are particularly attractive since they, in principle, offer a generic approach to anion sensing. That is, selectivity of the polymer membrane for one anion over others can be altered merely by changing the structure of the ionophore or ion binding site(s) doped within the organic polymer film. Moreover, such electrodes are well-suited for measurements in complex biological samples, because, unlike the mixed precipitate membranes, they suffer little or no interference from endogenous proteins.

As shown in Fig. 1, there are four types of ionophore that can be doped into polymer films to achieve potentiometric anionic response. These include dissociated ion exchangers, charged carriers, neutral carriers, and reactive carriers. To date, the vast majority of polymer membrane-based anion sensors reported in the literature utilize lipophilic dissociated ion exchangers as membrane active components (e.g., quaternary ammonium or phosphonium species; see Fig. 2). Such membranes develop phase boundary potentials via a classical ionexchange mechanism in which the more

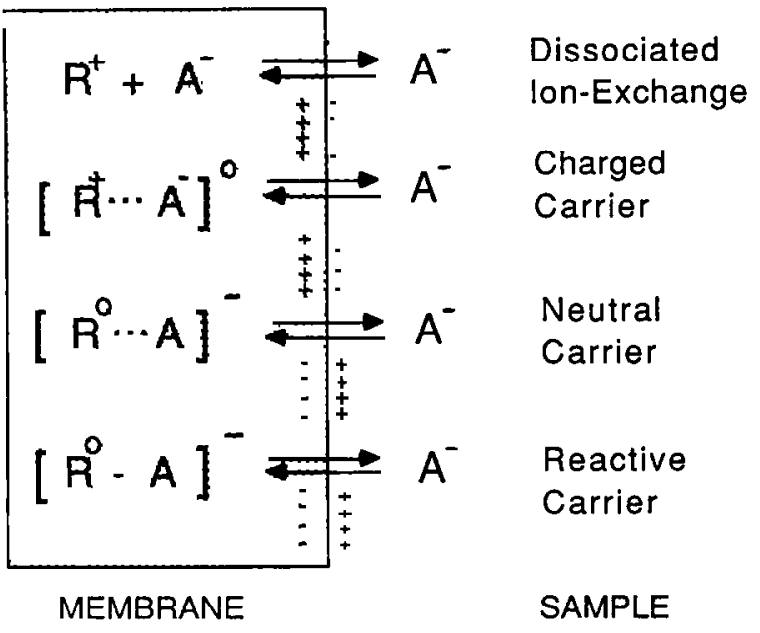

Fig. 1. Four possible mechanisms by which anions can interact with compounds doped into polymer membranes.

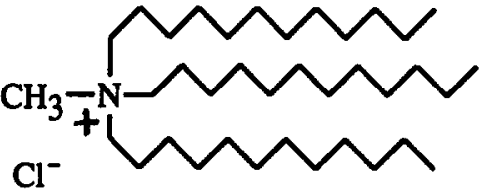

1

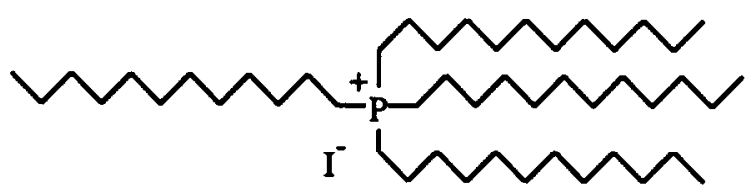

$\underline{2}$

Fig. 2. Structures of tridodecylmethylammonium chloride (1) (TDMAC) and tetradodecylphosphonium iodide (2) (TDPI), often used to prepare anion-selective membrane electrodes.

hydrophilic counter-anions in the membrane are completely dissociated from the lipophilic, positively charged cation sites. Consequently, anion interactions with the membrane phase, and thus membrane transport selectivity, are dictated primarily by the partition coefficients of given anions between the aqueous test solution and the solvent or plasticizer used to prepare the polymer film. This results in the so-called Hofmeister selectivity pattern (Hofmeister, 1888), where the more hydrophobic anions are preferred $\left(\mathrm{ClO}_{4}^{-}>\mathrm{SCN}^{-}>\mathrm{I}^{-}>\mathrm{Br}^{-}>\mathrm{Cl}^{-}>\right.$ $\mathrm{HCO}_{3}^{-}$).

In accordance with existing permselective membrane theory (Morf, 1981), the selectivity coefficients of such dissociated ion-exchangerbased membranes can be expressed quantitatively as follows:

$$
k_{i, j}^{\text {pot }}=\frac{\mu_{j} k_{j}}{\mu_{i} k_{\imath}}
$$

where $\mu_{i}$ and $\mu_{j}$ are the mobilities of ions $i$ and $j$ in the membrane phase, and $k_{i}$ and $k_{j}$ are the partition coefficients of primary (i) and interfering anions $(j)$, respectively.

To deviate from Hofmeister behavior, polymeric membranes, for example those prepared with plasticized PVC, must be doped with lipophilic molecules that interact selectively with anions via any one of the three remaining mechanisms shown in Fig. 1: (a) binding of the anion to a positively charged site on the dopant molecule (associated charged carrier); (b) binding 
of the anion to a neutral form of the dopant, thereby creating a negatively charged complex in the membrane phase (neutral carrier); or (c) a chemical reaction (bonds broken) between the anion and dopant molecules to form a negatively charged anion adduct.

In the case of charged carriers, potentiometric selectivity for one anion over another can be expressed as follows (Morf, 1981):

$$
k_{i, j}^{\mathrm{pot}}=\frac{\mu_{j s} k_{j} k_{j s}^{\mathrm{eq}}}{\mu_{i s} k_{i} k_{i s}^{\text {eq }}}
$$

where the terms $\mu$ and $k$ are as in eqn. (2), is and $j s$ denote a complex between the carrier and primary ion $(i)$ or interferent ion $(j)$, respectively, and $k^{\mathrm{eq}}$ is the equilibrium binding constant for the direct interaction of the carrier and the ionic species in the membrane phase. While relative partition coefficients of the anions are still important, non-Hofmeister selectivity can be achieved by employing charged species that bind one anion with greater affinity than another (i.e., $k_{i s}^{\mathrm{eq}} \gg k_{j s}^{\mathrm{eq}}$.

The selectivity of membranes based on neutral carriers is dependent on the mobility of the charged complexes in the membrane $\left(\mu_{j s}, \mu_{i s}\right)$, their partition coefficients $\left(k_{j s}, k_{i s}\right)$, and the equilibrium binding constants $\left(k_{l s}^{\mathrm{eq}}, k_{j s}^{\mathrm{eq}}\right)$ of the ions with the carriers in the membrane phase:

$$
k_{i, j}^{\text {pot }}=\frac{\mu_{j s} k_{j s} k_{j s}^{\text {eq }}}{\mu_{i s} k_{i s} k_{i s}^{\text {eq }}}
$$

Equation (4) is also applicable to polymeric membrane electrodes doped with neutral reactive carriers (see Fig. 1) such as trifluoroacetyl-pbutylbenzene, used to prepare carbonate-selective ISEs (Herman \& Rechnitz, 1974; Meyerhoff et al., 1987) (see structure 9 in Fig. 23, Section 4.1). This is because the only mechanistic difference between the neutral carrier- and reactive carrierbased electrodes is that potentiometric response for the latter is based upon ion-ionophore covalent bond formation while response for the former is governed solely by a reversible ionionophore electrostatic interaction.

Identifying ionophore-type organic compounds that exhibit unique and highly selective interactions with anions remains a challenge. With the exception of the reactive carrier-type carbonateselective ionophore system (Meyerhoff et al., 1987), many of the polymer membrane anion electrodes described to date do in fact display the classical Hofmeister selectivity pattern. Even some commercial electrodes which are advertised as being $\mathrm{NO}_{3}^{-}$and $\mathrm{Cl}^{-}$'selective' sensors are formulated with dissociated ion-exchanger-type membranes, and thus they too suffer severe interference from lipophilic anions such as $\mathrm{I}^{-}, \mathrm{SCN}^{-}$, $\mathrm{ClO}_{4}^{-}$and organic anions. Consequently, there is a need to identify new polymer membrane chemistries that will yield potentiometric anion sensors with non-Hofmeister selectivities.

\subsection{Heparin sensor}

Although polymer membranes prepared with quaternary ammonium species such as TDMAC display Hofmeister selectivity toward small anions, the response of such membranes towards larger anions has yet to be investigated. Recently, while examining the behavior of polymeric membranes doped with certain quaternary ammonium species, we observed some very unexpected potentiometric responses to large polyanionic species (Ma et al., 1992). In particular, membranes prepared with specific formulations of tridodecylmethylammonium chloride (TDMAC; see Fig. 2), plasticizer and PVC were found to display rather large and reproducible responses to heparin, a widely used macromolecular anticoagulant.

As depicted in Fig. 3, heparin is an anionic rodlike polysaccharide copolymer consisting of alternating uronic/iduronic acid and sulfated/ sulfonated glucosaminc residucs. The average molecular weight of the polymer is 15000 daltons (Danishefsky et al., 1989). Heparin acts as a potent anticoagulant by virtue of its strong electrostatic interaction with antithrombin III (ATIII), causing the formation of heparin-ATIII complexes which inhibit enzymes involved in the coagulation cascade (O'Reilly, 1985). Protamine and polybrene (a polyquaternary ammonium salt species) reverse the anticoagulating activity of heparin by binding tightly with its polyanionic structure. It is also known that the tridodecylmethylammonium ion (TDMA) itself forms complexes with heparin (Grode et al., 1972), suggesting that, within a polymeric membrane, TDMA could act as a charged carrier with respect to its interaction with heparin at a membrane/ sample interface (i.e., the response governed by eqn. (2) above).

Using a conventional electrode configuration, the heparin response of membranes prepared 


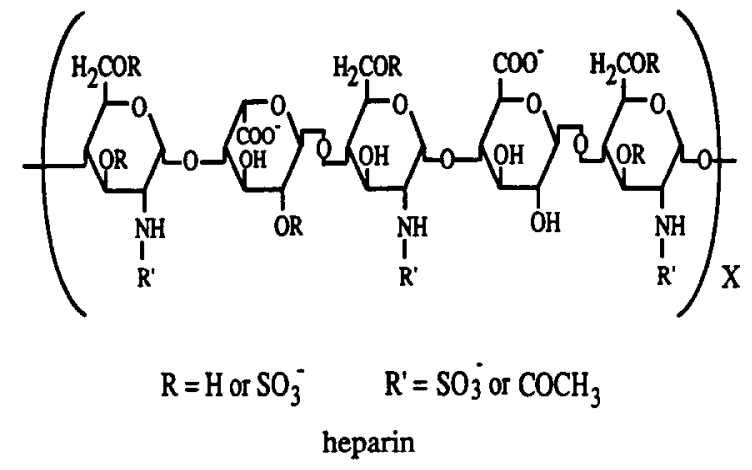

Fig. 3. Oligosaccharide sequence of carbohydrate units in heparin.

from widely varying formulations (Table 1) has been examined (Ma et al., 1992). Membranes with optimum response toward heparin contain 33 wt\% plasticizer (dioctyl sebacate (DOS)), $66 \mathrm{wt} \%$ PVC, and $\sim 1.5 \mathrm{wt} \%$ TDMAC. This composition is significantly different (much less plasticizer and more PVC) from that typically used in conventional ISE polymer membranes (Craggs et al., 1974). It is interesting to note that membranes doped with the tetra-alkyl analog of TDMAC, tetradodecylammonium chloride, exhibit negligible heparin response, suggesting that some accessibility to the positively charged nitrogen atom is required for heparin interaction within the membrane. On the other hand, a much smaller response to heparin is observed when only one or two of the alkyl chains of the quaternary ammonium species are $\geqslant \mathrm{C}_{8}$ and the rest are small, less lipophilic methyl groups (e.g., trimethylhexadecylammonium, dioctadecyldimethylammonium, etc.). These studies indicate that the specific structure of the quaternary ammonium species doped within the polymeric membrane is a very important factor in determining the magnitude of the potentiometric response to heparin.

The magnitude of potentiometric response of an optimized TDMAC-based polymer membrane toward heparin of 1.4 units ml ${ }^{-1}$ (or $8.4 \mu \mathrm{g} \mathrm{ml}^{-1}$ ) in the presence of physiological levels of chloride ion (i.e. $\sim 0.12 \mathrm{~mol} \mathrm{l}^{-1}$ ) is $42 \mathrm{mV}$, and the membrane electrode reaches equilibrium in less than $3 \mathrm{~min}$. The sensor does not respond to heparin when the polymer membrane of the sensor is covered with a thin dialysis membrane (with $\mathrm{MW}$ cutoff $=12000$ ). This indicates that the response observed is due to high molecular weight heparin, and not to small anionic impurities present in the heparin preparation. More importantly, when protamine is added to a solution containing heparin. the potential of the electrode becomes more positive, indicating that the concentration of free heparin is greatly reduced. Given the strong binding interaction between heparin and protamine (Godal, 1960), this observation is expected if the electrode is sensing the amount of free heparin in the sample solution.

Preliminary feasibility studies regarding the

TABLE 1 Potentiometric heparin response of TDMAC-based PVC membranes prepared with various membrane compositions ${ }^{a}$

\begin{tabular}{|c|c|c|c|c|}
\hline Membrane & $\begin{array}{l}\Delta \mathrm{E}^{b}, \mathrm{mV} \\
0-1.4 \mathrm{U} \mathrm{ml}^{-1} \text { heparin } \\
\text { in } 0.12 \mathrm{~mol}^{-1} \mathrm{NaCl}\end{array}$ & PVC (wt\%) & DOS (wt\%) & TDMAC (wt\%) \\
\hline $\mathbf{a}$ & -11.6 & 33.0 & $66 \cdot 0$ & 1.0 \\
\hline b & $-10 \cdot 4$ & $32 \cdot 6$ & 65.9 & 1.6 \\
\hline$c$ & $-2 \cdot 1$ & $32 \cdot 7$ & $65 \cdot 3$ & $2 \cdot 0$ \\
\hline d & -7.0 & 32.4 & $65 \cdot 1$ & 2.5 \\
\hline e & $-5 \cdot 0$ & 32.4 & 64.6 & 3.0 \\
\hline $\mathrm{f}$ & -30.7 & 48.9 & 50.5 & $1 \cdot 1$ \\
\hline g & $-41 \cdot 8$ & $65 \cdot 8$ & $33 \cdot 3$ & 0.9 \\
\hline h & -38.0 & $73 \cdot 1$ & $26 \cdot 0$ & 0.9 \\
\hline $\mathrm{i}$ & $-44 \cdot 4$ & 65.5 & $33 \cdot 1$ & 1.4 \\
\hline j & $-31 \cdot 0$ & 66.4 & $33 \cdot 1$ & 0.5 \\
\hline $\mathrm{k}$ & $-45 \cdot 0$ & 65.5 & $32 \cdot 5$ & $2 \cdot 0$ \\
\hline
\end{tabular}

${ }^{a}$ From Ma et al. (1992), with permission.

${ }^{b}$ Average of duplicates obtained from three electrodes. 
use of this polymer membrane electrode for detection of heparin in undiluted human plasma samples have also been conducted. As shown in Fig. 4, the electrode exhibits a linear response with respect to the logarithm of heparin concentration in the range of 1.0 to $9.8 \mathrm{U} \mathrm{ml}^{-1}$ $\left(6.0-58.8 \mu \mathrm{g} \mathrm{ml}^{-1}\right)$ with a slope of $28.2 \mathrm{mV}$ per decade. The sensitivity of the electrode appears to be more than adequate to meet most clinical needs, particularly in surgical procedures where a dose of 2-8 $\mathrm{U} \mathrm{ml}^{-1}$ (i.e., $12-48 \mu \mathrm{g} \mathrm{ml}^{-1}$ ) of heparin is often used (Jaques, 1979).

To gain further insight into the response characteristics of the heparin-sensitive membrane, the electrode's response toward various related compounds has been examined (Table 2). Among the glycosaminoglycans tested, the electrode yields an increased potentiometric response correlating to the degree of sulfate/ sulfonate content of these compounds. Interestingly, the electrode displays no measurable response to poly(vinylsulfate) (PVS), a highlysulfated polymer, nor to sulfated/sulfonated or nonsulfated glucosamine residues which are the

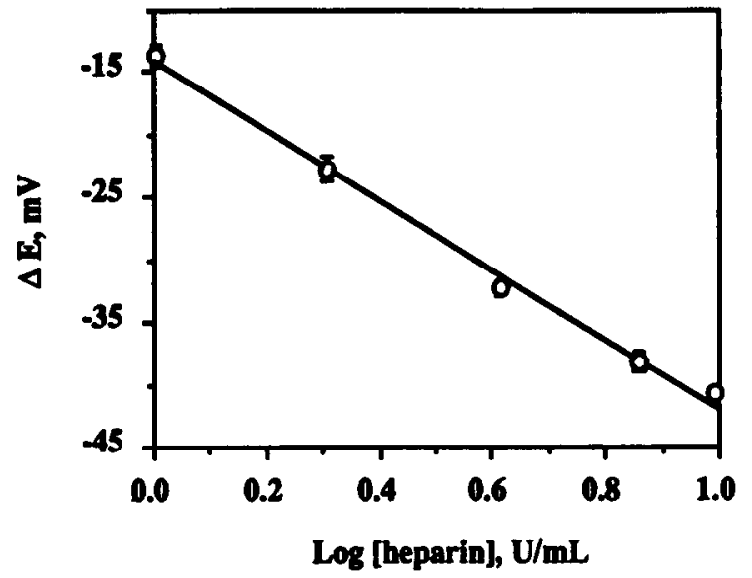

Fig. 4. Typical calibration curve for heparin sensor toward heparin in fresh human whole plasma sample (citrated). Results are the mean \pm s.d. for duplicates of two different electrodes. (From Ma et al. (1992), with permission.)

major monosaccharide building blocks of heparin. These results indicate that heparin's high sulfate/sulfonate content and its specific polymeric structure are both essential for its inter-

TABLE 2 Potentiometric response of heparin sensor toward various compounds ${ }^{a, b}$

\begin{tabular}{|c|c|c|}
\hline Tested compounds ${ }^{c}\left(12 \mu \mathrm{g} \mathrm{ml}^{-1}\right)$ & $\Delta E^{d}, \mathrm{mV}^{e}$ & $\begin{array}{l}\text { Sulfate content } \\
\text { (wt\%) }\end{array}$ \\
\hline \multicolumn{3}{|l|}{ Glycosaminoglycans } \\
\hline heparin & -50 & 13 \\
\hline dermatan sulfate & -25 & 9 \\
\hline chondroitin sulfate $A$ & -10 & 7 \\
\hline hyaluronic acid & 0 & 0 \\
\hline Poly(vinyl sulfate) $f$ & 0 & 62 \\
\hline \multicolumn{3}{|l|}{ Glucosamine residues } \\
\hline glucosamine & 0 & 0 \\
\hline glucosamine 2 -sulfate & 0 & 25 \\
\hline glucosamine 3-sulfate (free acid) & 0 & 27 \\
\hline glucosamine 6-sulfate (free base) & 0 & 27 \\
\hline glucosamine 2,3 -disulfate & 0 & 42 \\
\hline
\end{tabular}

${ }^{a}$ From Ma et al. (1992), with permission.

${ }^{b}$ All compounds were prepared in $0.12 \mathrm{~mol}^{-1} \mathrm{NaCl}$ solution at the same concentration (i.e., $12 \mu \mathrm{g} \mathrm{ml}^{-1}$ ). For heparin, this concentration is equivalent to $2 \mathrm{U} \mathrm{ml}^{-1}$ activity.

${ }^{c}$ Unless otherwise specified, all compounds are in their sodium salt form.

${ }^{d}$ Average of duplicates obtained from three electrodes.

${ }^{e}$ Change in cell potential compared to solution of $0.12 \mathrm{~mol} \mathrm{l}^{-1} \mathrm{NaCl}$.

$f$ The [poly(vinyl sulfate)] may be different from the others since only the soluble part present in the supernatant is used; the nonsoluble part is filtered off. 
action with the TDMAC-doped membrane. Preliminary electrodialysis studies (Thoma et al., 1977) reveal that fluorescein-labeled heparin can permeate into the bulk phase of the TDMAC/ DOS/PVC membrane. These results suggest that the response mechanism of the sensor may resemble that observed with charged-carrierbased polymer membrane electrodes (see eqn. (3) above), which involves solvent extraction of the analyte into the organic membrane phase and concomitant ion-complexation of analyte with the carrier. The preferred selectivity toward heparin over its analogs and the sulfated/ sulfonated monomeric glucosamine residues may thus be due to the ability of heparin's many sulfate/sulfonate groups to interact simultaneously with a large number of relatively immobile, positively charged TDMA sites in the hydrophobic membrane. It is important to note that, as with other polymer membrane electrodes prepared with quaternary ammonium ionexchange species, the TDMAC-based heparin sensor does exhibit substantial response to more lipophilic anions such as salicylate and bromide (i.e., high single ion partition coefficients into the membrane - again, see eqn. (3)); however, these species would normally not be present at interfering levels in the blood of systemically heparinized patients undergoing open-heart surgery.

Given the importance and critical need for monitoring heparin levels, this new sensor may ultimately offer attractive advantages over existing approaches based on clotting time measurements. It is envisioned that proposed membrane chemistry could be implemented in a disposable single-use electrode format (similar to the Kodak's Ektachem design (Walter, 1983)) for rapid estimation of free heparin levels in undiluted blood. Work on demonstrating the clinical utility of this approach is currently in progress, as are efforts to understand more fully the exact mechanism of heparin response. In addition, we believe that the heparin sensor can also scrve as an excellent analytical tool to study heparin interactions with anti-thrombin III and other physiological proteins. That is, the ability to measure free concentrations of heparin by direct potentiometry should allow for the convenient determination of the association constants between heparin and a variety of blood proteins and potential antidotes.

\subsection{Metalloporphyrin-based anion sensors}

Recent studies in this laboratory (Brown et al., 1989; Chaniotakis et al., 1988, 1989; Park, 1991) and elsewhere (Sharp, 1975; Hodinár \& Jyo, 1988; Schulthess et al.. 1984, 1985; Wuthier, 1984; Glazier \& Arnold, 1989; Chang et al., 1990) have demonstrated that when plasticized PVC membranes are doped with certain organometallics or metal-ligand complexes, the resultant membranes exhibit potentiometric anion selectivity sequences markedly different from the Hofmeister pattern. For example, Table 3 summarizes the potentiometric selectivity coefficient data for membrane electrodes prepared with the $\mathrm{Sn}(\mathrm{IV}), \mathrm{Mn}(\mathrm{III})$ and $\mathrm{In}(\mathrm{III})$ porphyrins illustrated in Fig. 5 (at $1 \mathrm{wt} \%$

TABLE $3 \log k_{\mathrm{Cl}^{-}, j}^{\text {pot }}$ values for polymer membrane electrodes prepared with TDMAC and the metalloporphyrins shown in Figure $7^{a}$

\begin{tabular}{|c|c|c|c|c|c|}
\hline Anion & TDMAC $^{b}$ & $\operatorname{Mn}(\mathrm{TPP}) \mathrm{Cl}^{b}$ & $\begin{array}{l}\log k_{\mathrm{Cl}^{-}}^{\text {pot }} \\
\operatorname{Mn}(\mathrm{TPP}) \mathrm{Cl}^{b}\end{array}$ & $\mathrm{Sn}(\mathrm{TPP}) \mathrm{Cl}_{2}$ & $\operatorname{In}(\mathrm{OEP}) \mathrm{Cl}^{c}$ \\
\hline $\mathrm{Cl}^{-}$ & 0.0 & 0.0 & $0 \cdot 0$ & $0 \cdot 0$ & 0.0 \\
\hline $\mathrm{Br}^{-}$ & 0.6 & 0.3 & 1.0 & 0.1 & $0 \cdot 3$ \\
\hline $\mathbf{I}^{-}$ & $2 \cdot 8$ & 1.5 & $2 \cdot 3$ & $0 \cdot 1$ & 1.6 \\
\hline $\mathrm{ClO}_{4}^{-}$ & $4 \cdot 6$ & 1.5 & $2 \cdot 8$ & 0.4 & -0.2 \\
\hline $\mathrm{IO}_{4}^{-}$ & 4.0 & 1.8 & $2 \cdot 5$ & 0.2 & - \\
\hline $\mathrm{SCN}^{-}$ & 3.0 & $1 \cdot 3$ & $5 \cdot 2$ & $1 \cdot 3$ & 0.9 \\
\hline $\mathrm{Sal}^{-d}$ & $2 \cdot 7$ & $2 \cdot 1$ & $3 \cdot 5$ & $3 \cdot 8$ & 1.6 \\
\hline
\end{tabular}

\footnotetext{
${ }^{a}$ From Park et al. (1991), with permission.

${ }^{b}$ Evaluated in 0.05 M MES buffer, pH 5.5.

${ }^{c}$ Evaluated in $0.05 \mathrm{M}$ phosphate buffer, pH $7 \cdot 2$.

${ }^{d} \mathrm{Sal}^{-}$, salicylate.
} 


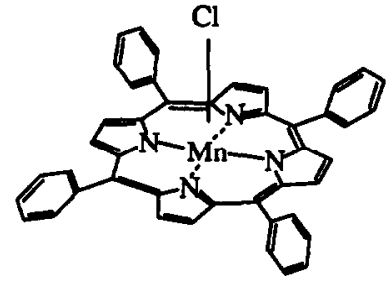

$\underline{3}$

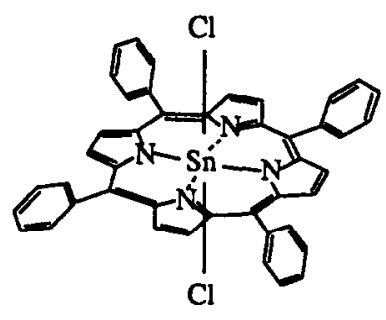

5

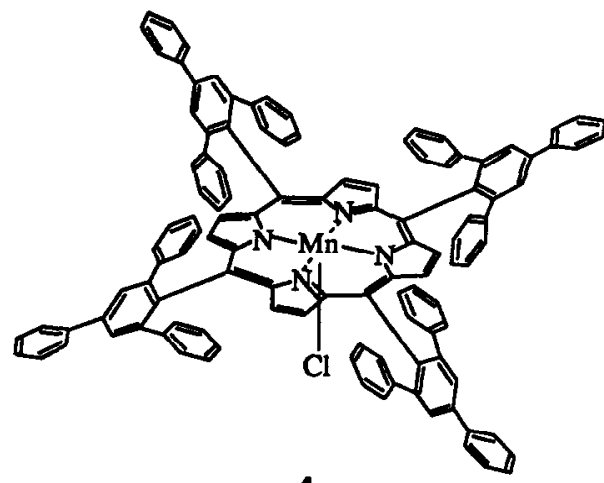

$\underline{4}$

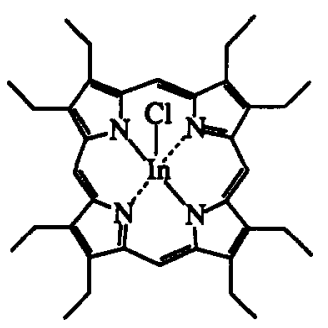

6

Fig. 5. Structures of 5, 10, 15, 20-tetraphenylporphyrinato manganese(III) chloride (3) (Mn(TPP)Cl); 5, 10, 15, 20-tetrakis(2, 4, 6-triphenylphenyl)porphyrinato manganese(III) chloride (4) (Mn(TPPP)Cl); 5, 10, 15, 20-tetraphenylporphyrinato tin(IV) dichloride (5) $\left(\mathrm{Sn}(\mathrm{TPP}) \mathrm{Cl}_{2}\right.$; and 2, 3, 7, 8, 12, 13, 17, 18-octaethylporphyrinato indium(III) chloride (6) (In(OEP)Cl).

porphyrin, $66 \mathrm{wt} \%$ plasticizer and $33 \mathrm{wt} \% \mathrm{PVC}$ ). For comparison purposes, the selectivity data for membranes prepared with TDMAC (Fig. 2) toward small anions is also provided. It can be seen that the observed potentiometric anion response of the porphyrin-based membranes deviates substantially from the Hofmeister pattern found with TDMAC-based membranes. Within the series of porphyrins examined, anion selectivity also varies, depending on the nature of the metal center, its oxidation state, and the peripheral structure of the porphine ring surrounding the central metal. For example, the anion selectivity of $\mathrm{Mn}$ (III) porphyrins can be altered by sterically hindering accessibility of anions to the central $\mathrm{Mn}$ (III) axial ligand site. Electrodes prepared with $\mathrm{Mn}$ (TPPP)Cl-doped membranes (compound $\underline{4}$ in Fig. 5) exhibit significantly enhanced response to thiocyanate relative to all of the other anions tested (Brown et al., 1989) (also relative to unhindered $\mathrm{Mn}(\mathrm{TPP}) \mathrm{Cl}, \underline{3}$ in Fig. 5). Membranes prepared with $\mathrm{Sn}$ (IV) porphyrins, such as $\mathrm{Sn}$ (TPP) $\mathrm{Cl}_{2}$ (compound $\underline{5}$ in Fig. 5), respond with relatively high selectivity toward salicylate, an aromatic carboxylate (Chaniotakis et al., 1989). In(III) porphyrin-based membranes, while not exhibiting a high degree of preference for any one anion, do respond potentiometrically to chloride ions to a greater extent than any of the other metalloporphyrin-based carriers studied (Park et al., 1991).

The unique selectivity sequences displayed by these metalloporphyrin polymer membrane electrodes suggest that such sensors can be used for practical analytical measurements of the preferred ions in complex biological samples. Figure 6 illustrates the typical calibration curves observed for the $\mathrm{Sn}(\mathrm{TPP}) \mathrm{Cl}_{2-}$ and In(OEP)Clbased membranes toward salicylate and chloride ions, respectively. It is interesting to note that the response of the In(OEP)Cl membrane to chloride is super-Nernstian, with slopes often approaching $85 \mathrm{mV}$ per decade. The origin of this behavior is not yet fully understood. Nevertheless, this sensor has been used as a detector in a flow-injection analysis (FIA) system to quantitate chloride ion levels accurately in serum samples (Park et al., 1991). Similarly, the high selectivity of the polymer membrane electrode prepared with $\mathrm{Mn}(\mathrm{TPPP}) \mathrm{Cl}$ for thiocyanate over chloride has enabled this sensor to be used as a detector for the 

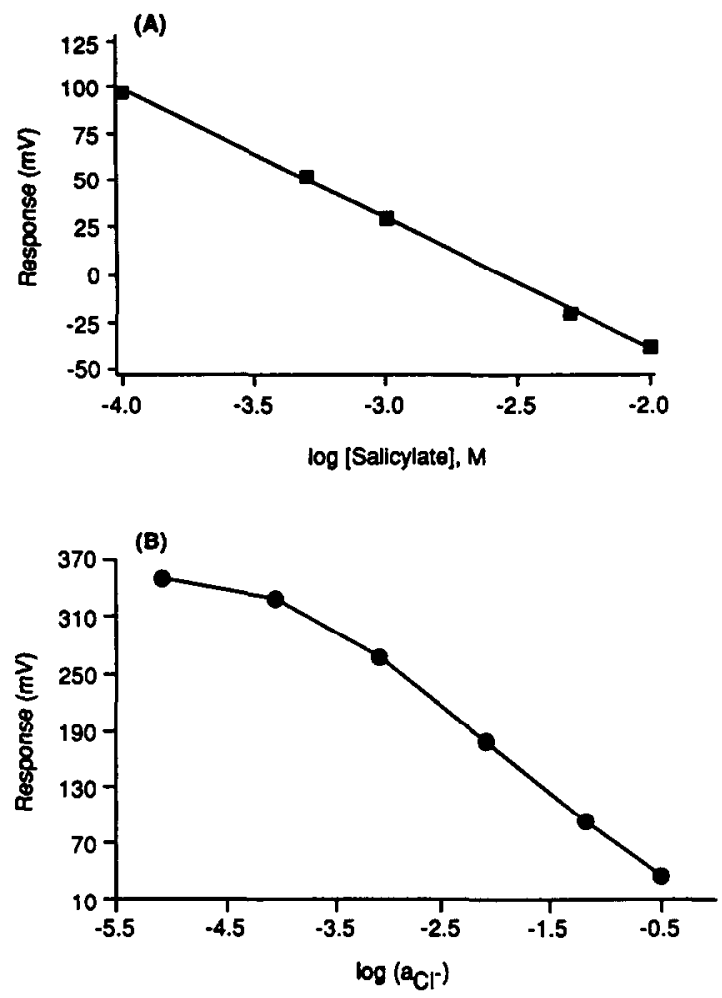

Fig. 6. Typical calibration curves for polymer membrane electrodes prepared with $\mathrm{Sn}(\mathrm{TPP}) \mathrm{Cl}_{2}$ and $\operatorname{In}(\mathrm{OEP}) \mathrm{Cl}$ towards salicylate $(A)$ and chloride $(B)$. (The latter from Park et al. (1991), with permission.)

direct FIA measurement of thiocyanate in human saliva samples (Brown et al., 1989). Good correlation with a classical colorimetric method (Bowler, 1944), based on $\mathrm{Fe}^{+3}$ complexation, has been obtained (Fig. 7). It is well known that elevated levels of thiocyanate in saliva and blood occur when individuals smoke cigarettes excessively, and thus the new Mn(TPPP)Clbased electrode could prove valuable for rapidly assessing the thiocyanate levels in such samples (e.g., perhaps through the development of a disposable single-use electrode device).

Practical application of the salicylate-selective membrane electrode doped with $\mathrm{Sn}(\mathrm{TPP}) \mathrm{Cl}_{2}$ has also been achieved through the accurate detection of salicylate in urine samples (Meyerhoff et al., 1989). Interpreting results for measurements of salicylate in blood samples with this electrode is, however, complicated by the fact that a very large fraction of the total salicylate is bound to proteins (Stewart \& Watson, 1987). Indeed, the new electrode detects 'free' salicylate levels while the conventional colorimetric procedures measure total salicylate concentration ('free' plus 'bound').

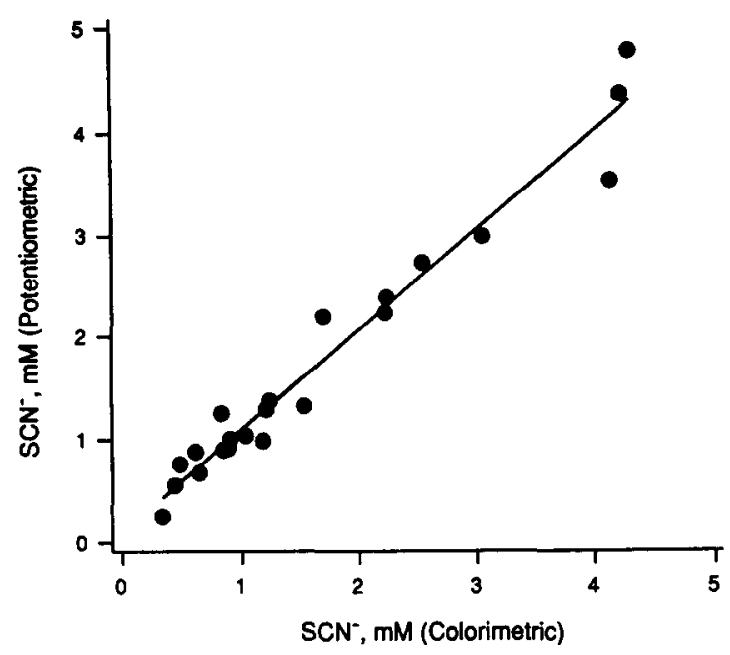

Fig. 7. Correlation data for thiocyanate measured in human saliva using an Mn(TPPP)Cl-based membrane electrode versus that of a conventional colorimetric method. (Adapted from Brown et al. (1989), with permission.)

The former is the physiologically active form of the compound. In protein-free serum samples, correlation between salicylate values determined by the porphyrin-based electrode and a colorimetric method is quite good (Table 4). We believe, therefore, that electrodes prepared with Sn(IV)porphyrin membranes could provide a convenient new tool for pharmacologists to study the active form of aspirin and other salicylates in living subjects.

Although practical bioanalytical applications of the porphyrin-based electrodes have already been demonstrated, the exact membrane chemistries leading to the observed potentiometric anion responses and selectivities are not completely resolved. The possible mechanisms for interactions of anions with metalloporphyrins at the polymer membrane/sample interface are based upon their coordination as axial ligands with the central metal. As shown in Fig. 8, phase boundary potentials dependent on the bathing anion activities can evolve from several possible equilibrium reactions at this interface. When the metal center is in a stable +2 oxidation state (e.g., $\mathrm{Co}$ (II) and $\mathrm{Ru}(\mathrm{II})$ porphyrins; Huser et al., 1990). the overall charge on the metalloporphyrin is zero, and thus the porphyrin complex can serve only as a neutral carrier ((A), Fig. 8), and eqn. (4) in Section 2.2 should apply with respect to selectivity. On the other hand, when the stable oxidation state of the metal is +3 (i.e., the $\mathrm{Mn}$ (III) or In(III) porphyrins described above), a boundary 
TABLE 4 Analytical recovery of salicylate added to protein-free serum and human urine using $\mathrm{Sn}(\mathrm{TPP}) \mathrm{Cl}_{2}-$ based membrane electrode ${ }^{a}$

\begin{tabular}{|c|c|c|c|}
\hline \multirow{2}{*}{ 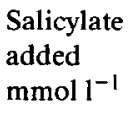 } & \multicolumn{2}{|c|}{ Salicylate found, $\mathrm{mmol} \mathrm{l}^{-1}$} & \multirow{2}{*}{$\begin{array}{l}\text { Avg \% } \\
\text { recovery } \\
\text { (electrode) }\end{array}$} \\
\hline & Electrode $^{h}$ & Colorimetric $^{c}$ & \\
\hline \multicolumn{4}{|l|}{ Serum $^{d}$} \\
\hline 0.00 & $0.10 \pm 0.01$ & $<0 \cdot 14$ & \\
\hline 0.64 & $0.77 \pm 0.02$ & 0.71 & 105 \\
\hline 0.99 & $1.13 \pm 0.07$ & 1.06 & 104 \\
\hline $1 \cdot 60$ & $1 \cdot 64 \pm 0 \cdot 10$ & 1.61 & $96 \cdot 2$ \\
\hline \multicolumn{4}{|l|}{ Urine } \\
\hline 0.00 & $0.23 \pm 0.01$ & & \\
\hline 0.79 & $0.98 \pm 0.03$ & & $94 \cdot 9$ \\
\hline $1 \cdot 24$ & $1 \cdot 44 \pm 0 \cdot 10$ & & 97.6 \\
\hline 1.99 & $2.27 \pm 0.10$ & & 103 \\
\hline
\end{tabular}

${ }^{a}$ From Chaniotakis et al. (1989), with permission.

${ }^{b}$ Average of three determinations \pm one standard deviation.

'Single measurement performed on Du Pont ACA instrument at the University of Michigan Hospitals.

${ }^{d}$ Fisher control serum.

potential is derived from two possible mechanisms, either addition of the anion as a sixth ligand yielding a negatively charged complex (B), or equilibrium binding of the anion as a fifth ligand (displacing the original fifth ligand) in an associative charge carrier type arrangement (C). A combination of both mechanisms is also possible, and this may be responsible for the super-Nernstian response of the $\operatorname{In}(\mathrm{OEP}) \mathrm{Cl}$ electrode system shown in Fig. 6. Finally, if the metal center is in the +4 oxidation state (D), such as $\mathrm{Sn}(\mathrm{TPP}) \mathrm{Cl}_{2}$, an associative charged carrier type mechanism should dominate (assuming that the anionic ligands are not completely dissociated from the metalloporphyrin structure in the membrane phase; if so, Hofmeister selectivity would be observed).

In many cases, the coordination of neutral water molecules to axial ligand sites can also occur (see Fig. 8(E) for the case where the metal center is in the +3 oxidation state, as an example). A deprotonation equilibrium reaction across the membrane/sample interface, the position of which is dependent on the $\mathrm{pH}$ of the sample, yields anion-selective membranes that also respond to $\mathrm{pH}$ changes. All $\mathrm{Mn}$ (III)-porphyrinbased membranes exhibit such $\mathrm{pH}$ response (Chaniotakis et al., 1988), necessitating the use of a pH 5. 5 MES (morpholinoethane-sulfonic acid)
(A)

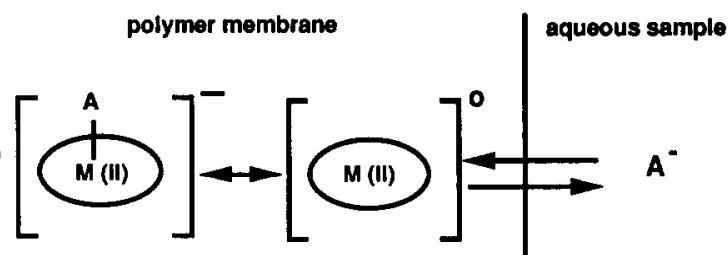

(B)

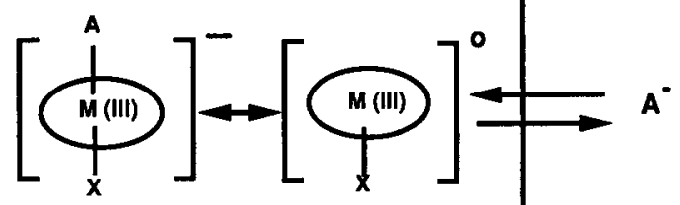

(C)

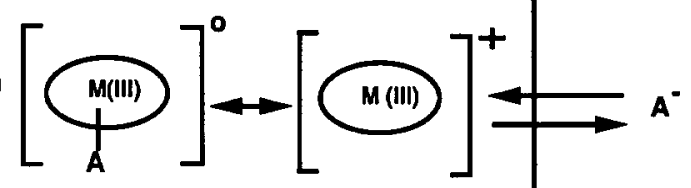

(D)

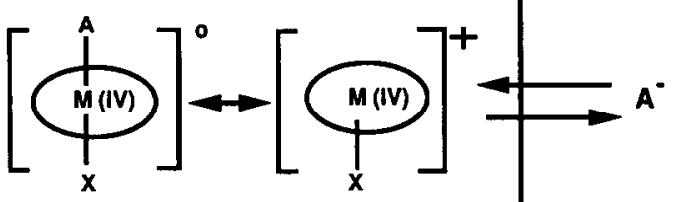

(E)

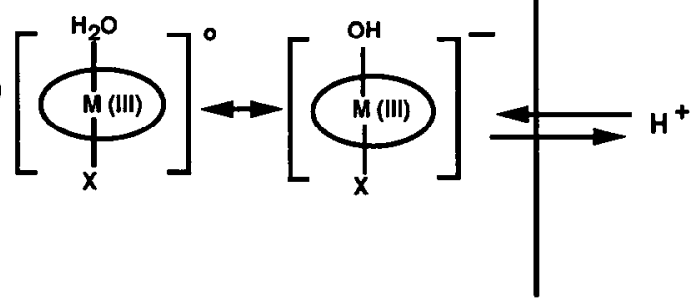

Fig. 8. Possible mechanisms by which an anion can interact with metalloporphyrins doped into the polymer membrane of an anion-selective electrode.

buffer to evaluate anion responses. $\mathrm{Sn}(\mathrm{TPP}) \mathrm{Cl}_{2-}$ based membranes also show a large response to $\mathrm{pH}$. In contrast, membranes doped with $\mathrm{In}(\mathrm{OEP}) \mathrm{Cl}$ exhibit relatively little $\mathrm{pH}$ response, particularly in the range of $\mathrm{pH} 5-9$. Figure 9 illustrates the difference in potentiometric $\mathrm{pH}$ response between the $\mathrm{Sn}(\mathrm{TPP}) \mathrm{Cl}_{2^{-}}$and In(OEP)Cl-doped polymer membranes. Evidence for aquation of the metalloporphyrin playing a critical role in the $\mathrm{pH}$ response of metalloporphyrin-doped membranes comes from radiotracer studies with ${ }^{3} \mathrm{H}_{2} \mathrm{O}$. As shown in Fig. 10, membranes doped with the Sn(IV)-porphyrin uptake ${ }^{3} \mathrm{H}_{2} \mathrm{O}$ at a significantly greater rate than either blank PVC membranes or those doped with In(OEP)Cl. The fact that the In(OEP)Clbased membrane exhibits minimal $\mathrm{pH}$ response suggests that this sensor could ultimately be used 


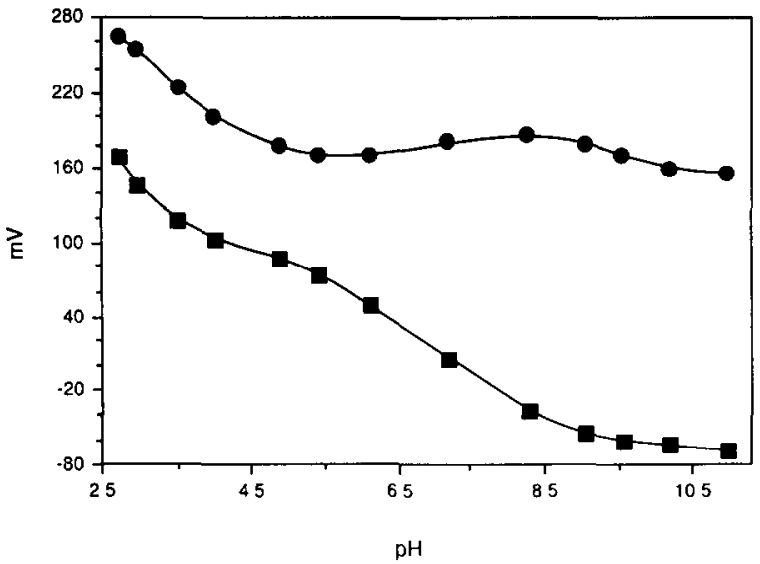

Fig. 9. Potentiometric $p H$ response of membrane electrodes prepared with $\mathrm{In}(\mathrm{OEP}) \mathrm{Cl}(\mathbf{O})$ and $\mathrm{Sn}(\mathrm{TPP}) \mathrm{Cl}_{2}(\mathbf{D})$. (From Park et al. (1991), with permission.)

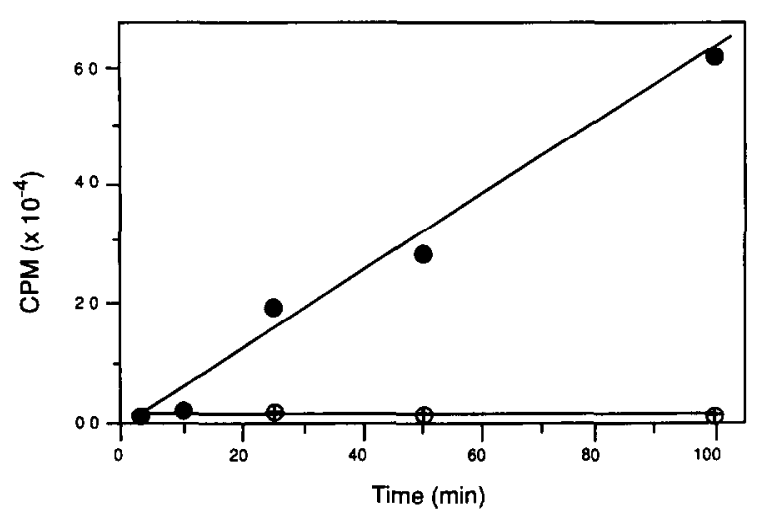

Fig. 10. Uptake of ${ }^{3} \mathrm{H}_{2} \mathrm{O}$ by polymer membranes doped with $\operatorname{In}(\mathrm{OEP}) \mathrm{Cl}(+), \mathrm{Sn}(\mathrm{TPP}) \mathrm{Cl}_{2}(\mathrm{O})$, and an undoped $\mathrm{PVC}$ membrane (O). (From Park et al. (1991), with permission.)

to measure chloride in undiluted samples at physiological $\mathrm{pH}$.

It is clear from the above data generated in this laboratory, as well as from a growing number of literature reports from other investigators (Chang et al., 1990), that metalloporphyrins and other related metal-ligand complexes could offer unique opportunities in the design of useful polymer membrane-type anion sensors. While further studies are needed to fully resolve the exact nature of anion interactions with the porphyrins at the membrane/sample interface, synthesis of new lipophilic metal-centered complexes with novel anion binding properties is warranted. Indeed, it would be interesting to determine whether the incorporation of In(III) rather than Mn(III) within the sterically hindered triphenyl-tetraphenylporphyrin structure (TPPP) (see compound 4 in Fig. 5) could yield a further enhancement in chloride ion selectivity.

\subsection{Electropolymerized porphyrin films for anion sensing}

A potential alternative to using dissolved metalloporphyrins as carriers in conventional PVC-type polymeric films would be to use polymerized forms of these porphyrins directly deposited on conductor electrodes. Such a scheme would be analogous to the solid-contact electrode design, except that potentiometric anion sensing could be achieved through selective interactions of given anions directly with the poly(porphyrin) film, not with a monomeric porphyrin species doped into a highly viscous organic phase (i.e., plasticized PVC).

There have been a number of recent literature reports that propose the use of chemically modified electrodes (CMEs), particularly ones prepared by electropolymerization methods, as potentiometric ion sensors (Heineman et al., 1980; Jin et al., 1991; Dong et al., 1988a, b; Lu et al., 1989; Karagozler et al., 1991). For example, Dong and coworkers have utilized glassy carbon electrodes modified with poly(pyrrole) films as anion sensors. In the oxidized form, poly(pyrrole) is a conjugate chain cation requiring a counteranion to maintain charge neutrality of the film. When the film is in contact with an aqueous solution, a phase boundary potential develops at the film/solution interface which is dependent on the activity of anions in the sample solution and the equilibrium constant for extraction of the anion into the film. Interestingly, the selectivity of such poly(pyrrole)-based sensors can be altered by changing the specific anion present in the supporting electrolyte during the electrochemical formation of the film (from monomeric pyrrole). Apparently, different size cavities or channels are formed within the film's structure, depending on the size and/or shape of the doping counteranion.

Given our results with monomeric porphyrins in PVC membranes, we have become intrigued with the prospects of utilizing electropolymerized forms of the metalloporphyrins to devise sensors with anion selectivities not attainable with existing polymer membrane/metal-complex systems. Most recently, Daunert et al . (1991) examined the potentiometric anion responses of electrodes 
modified with electropolymerized cobalt(II) tetrakis(o-aminophenyl)porphyrin films and found that such modified electrodes exhibit selective potentiometric response toward thiocyanate.

For initial studies, we thought it would be useful first to examine the anion response properties of unmetallated poly(porphyrins) in their fully conducting (oxidized) and nonconducting (reduced) states. As a model system, films of polymerized tetrakis ( $p$-aminophenyl)porphyrin ( $\operatorname{poly}\left(\mathrm{H}_{2}(p\right.$-TAPP $\left.\left.)\right)\right)$ formed on the surface of glassy carbon electrodes were employed. The polymer films are introduced onto the glassy carbon surface by constant-potential anodic electrolysis of the porphyrin monomer from a solution of dichloromethane containing a quaternary ammonium perchlorate salt (Bettelheim et al., 1987). The thickness of the film can be controlled by the electrodeposition time.

During preliminary testing, films that were first reduced electrochemically yielded relatively small potentiometric anion response, while those that were left in their oxidized state did in fact respond to a greater degree to certain anions (Table 5). Surprisingly, even though the oxidized films were formed in the presence of perchlorate as the sole supporting electrolyte anion, these moditied electrodes repeatedly exhibited a much

TABLE 5 Overall potentiometric response for unconditioned, poly( $\mathrm{H}_{2}(o$-TAPP $\left.) \mathrm{Cl}\right)$ films in $0.05 \mathrm{M} \mathrm{MES}$, $\mathrm{pH} 5 \cdot 5$, at $1 \times 10^{-2} \mathrm{M}$ anion concentration ${ }^{a, b}$

\begin{tabular}{lll}
\hline Anion & $\begin{array}{l}\text { Oxidized film } \\
\text { Change in potential } \\
(\mathrm{mV})\end{array}$ & $\begin{array}{l}\text { Reduced film } \\
\text { Change in potential } \\
(\mathrm{mV})\end{array}$
\end{tabular}

\begin{tabular}{lll}
\hline $\mathrm{I}^{-}$ & -171 & -25 \\
$\mathrm{SCN}^{-}$ & -87 & -49 \\
$\mathrm{ClO}_{4}^{-}$ & -84 & -59 \\
$\mathrm{Sal}^{-c}$ & -84 & -69 \\
$\mathrm{NO}_{3}^{-}$ & -63 & -35 \\
$\mathrm{Br}^{-}$ & -56 & -35 \\
$\mathrm{Cl}^{-}$ & -27 & -10 \\
$\mathrm{HCOO}^{-}$ & -20 & -27 \\
$\mathrm{~F}^{-}$ & -16 & -16 \\
$\mathrm{SO}_{4}^{-2}$ & -10 & -12 \\
\hline
\end{tabular}

${ }^{a}$ From Kliza \& Meyerhoff (1992), with permission. ${ }^{b}$ Films oxidized at $+1.2 \mathrm{~V}$ and reduced at $-0.1 \mathrm{~V}$ vs SSCE for $2 \mathrm{~min}$ following electropolymerization in $\mathrm{CH}_{3} \mathrm{CN}$ and $0.1 \mathrm{M}$ tetraethylammonium perchlorate.

'Sodium salicylate. greater response to iodide over perchlorate, as well as over a large number of other anions tested.

The potentiometric response of the oxidized poly $\left(\mathrm{H}_{2}(p\right.$-TAPP $\left.)\right)$-modified electrodes toward iodide is enhanced by soaking the modified electrode in $0.1 \mathrm{M} \mathrm{NaI}$ solution for $5 \mathrm{~min}$ prior to the potentiometric measurements. The dynamic response of such a conditioned electrode to standard additions of sodium iodide in $0.05 \mathrm{M}$ MES buffer, pH 5.5, was examined. The response is rapid $(<30 \mathrm{~s})$ and reasonably stable. When the potential is plotted as a function of the logarithm of iodide concentration (not shown in this paper), the response is linear over an iodide ion concentration range from $5 \times 10^{-5}$ to $0.1 \mathrm{M}$ $\left(r^{2}=0.998\right)$. The slope observed in the linear region is typically $58 \pm 1 \mathrm{mV}$ per decade.

It has been suggested that $\mathrm{H}_{2}(p$-TAPP) electropolymerizes via a mechanism similar to poly(aniline) (Iluang et al., 1986) and, as such, the final oxidized polymer would be expected to possess a significant number of positively charged sites, dependent on the $\mathrm{pH}$ of the bathing sample solution. In considering possible mechanisms for enhanced potentiometric response of both unmetallated and metallated poly(porphyrin)-modified electrodes, five distinctly different processes can be identified as potentially contributing to the overall response. These are illustrated schematically in Fig. 11.

Mechanism 1 involves anion exchange reactions with these positively charged sites on the polymer backbone of the oxidized poly(porphyrin) film.

A second ion-exchange process is possible (mechanism 2, Fig. 11) if supporting electrolyte (e.g., tetrabutylammonium ion) is entrapped within the polymer matrix, yielding fixed positively charged sites. The fact that fully reduced films, however, do not exhibit enhanced iodide response suggests that entrapped cationic sites do not play a major role in the observed iodide selectivity exhibited by the oxidized poly $\left(\mathrm{H}_{2}(p-\right.$ TAPP)) modified electrodes. Indeed, such entrapped cationic sites should still be present within the reduced films, and are in fact probably responsible for the small Hofmeister-type anion response pattern observed with the fully reduced electrodes (Table 4).

Mechanism 3 of Fig. 11 depicts a response mechanism in which redox-active species can permeate the poly(porphyrin) film and interact directly with the underlying electrode surface 


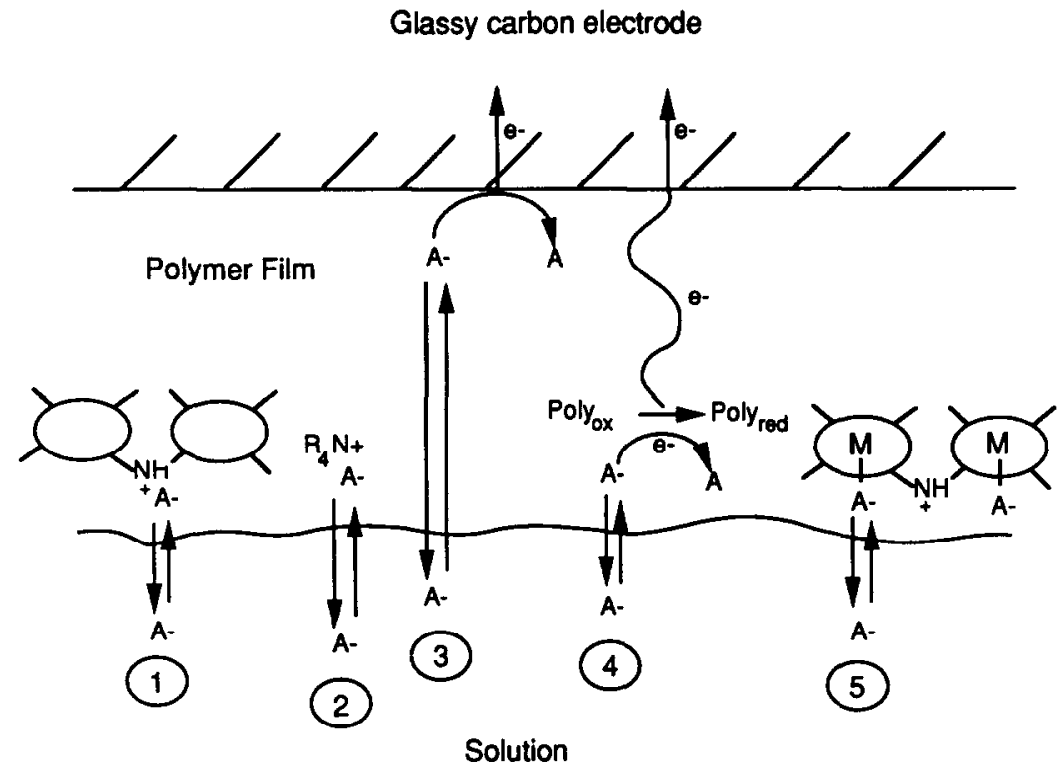

Fig. 11. Possible mechanisms for potentiometric response of an electropolymerized film-modified electrode: (1) ion-exchange process with positively charged polymer backbone; (2) ion exchange due to entrapped quaternary ammonium ion of supporting electrolyte; (3) redox response at the underlying electrode surface; (4) redox response due to redox reaction with conducting polymer; and (5) metal-anion interaction through axial ligand exchange.

(carbon). The fact that all of the poly(porphyrin) film-modified electrodes also exhibit large potentiometric response to other redox-active anions (e.g., ferricyanide etc.) indicates that direct redox electrochemistry, in addition to ionexchange-based phase boundary potentials, is occurring either at the underlying carbon electrode or within the poly(porphyrin) film (mechanism 4 of Fig. 11) when it is in an electrically conducting state (i.e., the oxidized form).

On the basis of the existing potentiometric data alone, it appears that the overall potentiometric anion response of the unmetallated $\operatorname{poly}\left(\mathrm{H}_{2}(p-\right.$ TAPP)) film-modified electrode may result from a combination of each of the first four mechanisms represented in Fig. 11. Spectroscopic data presented in Fig. 12, however, clearly verifies that a redox reaction between added iodide and the oxidized polymer film (mechanism 4 of Fig. 11) does take place. This figure illustrates how the spectrum of the oxidized film changes as iodide is added to the sample solution, presumably reducing the film. Based on this spectral data, enhanced potentiometric response to iodide of the oxidized film electrodes appears to be primarily due to a combination of mechanisms 3 and 4 . That is, a redox equilibrium exists between added iodide and the oxidized film, which favors oxidation of $\mathrm{I}^{-}$to $\mathrm{I}_{2}$ or $\mathrm{I}_{3}^{-}$(and entrapment of $\mathrm{I}_{2}$ or $\mathrm{I}_{3}^{-}$into the film) with concomitant reduction of the poly $\left(\mathrm{H}_{2}(p\right.$-TAPP $\left.)\right)$. This process can take place during the initial conditioning of the modified electrode in NaI solution (or during the first standard additions of very dilute iodide when obtaining calibration e.m.f. data). A more detailed discussion of this mechanism is presented elsewhere (Kliza \& Meyerhoff, 1992).

Mechanism 5 of Fig. 11 depicts the case when the poly(porphyrin) film is metallated. In this instance, analyte anions in the sample solution can bind directly as axial ligands to the metal centers of the poly(porphyrin), analogously to what occurs in plasticized PVC-type membranes doped with monomeric metalloporphyrins (see Section 2.3). On the basis of the above data for oxidized, unmetallated poly(porphyrin) films (i.e. iodide oxidation to iodine and eventual chemical reduction of the film), applying a final reduction potential to a metallated film after electropolymerization should eliminate iodide response and enable one to take advantage of the direct metalanion ligation reactions at the film/solution interface. Promising preliminary results for this concept are shown in Table 6, which compares the potentiometric anion responses for oxidized and reduced polymeric films of manganese(III) tetra(o-aminophenyl)porphyrin $\quad(\operatorname{poly}(\mathrm{Mn}(o-$ 


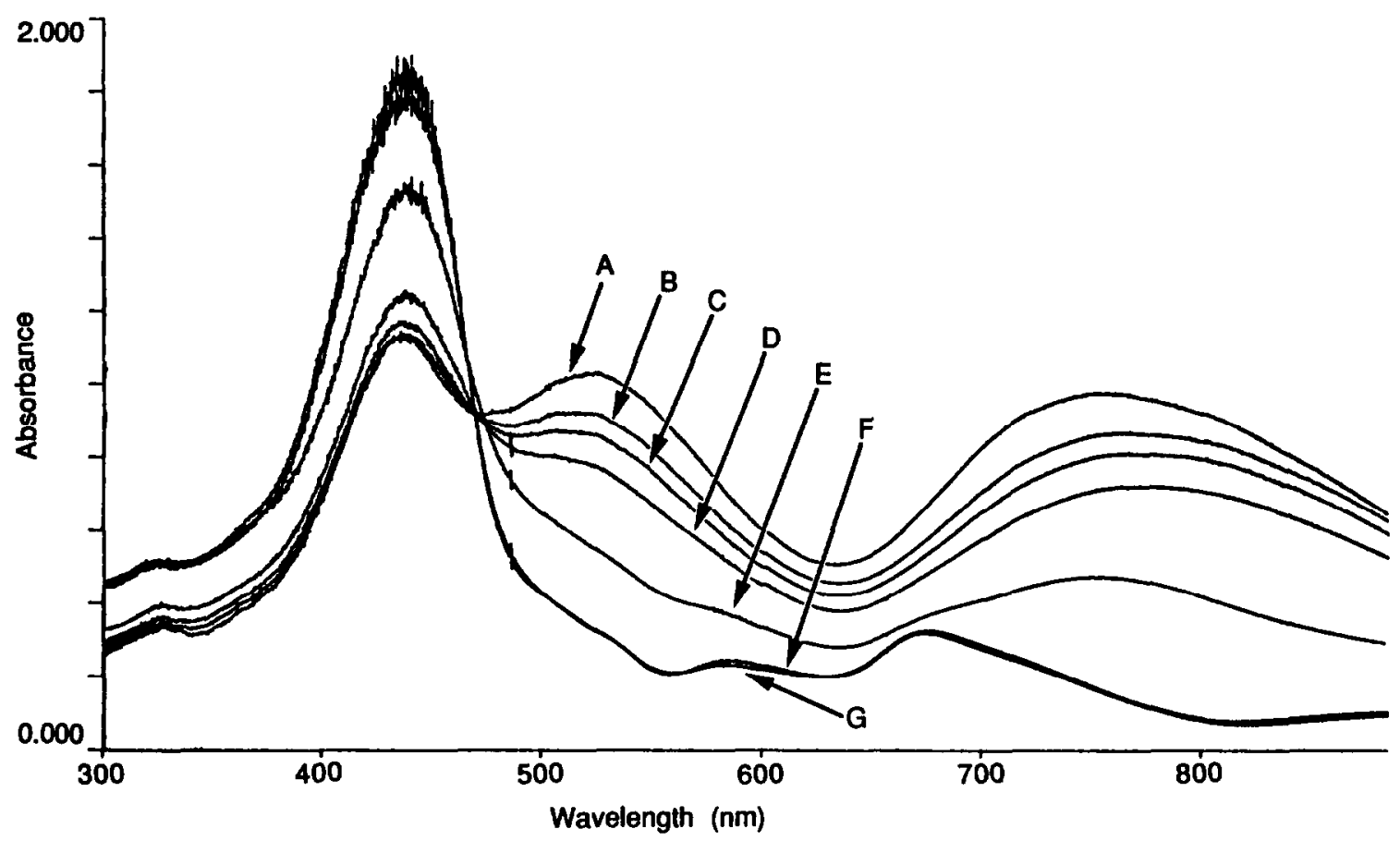

Fig. 12. UV-Vis spectra for electrochemically oxidized $(A)$, electrochemically reduced $(G)$ films of poly $\left(\mathrm{H}_{2}(\mathrm{p}-\mathrm{TAPP})\right.$ ) on $\mathrm{SnO} \mathrm{O}_{2}$ conducting glass electrodes (same electrode). (B)-(F) refer to spectra obtained for oxidized film after sequential additions of $N a I$ to the bathing solution at concentrations as follows: (B) $5 \times 10^{-6} \mathrm{M} ;(\mathrm{C}) 5 \times 10^{-5} \mathrm{M} ;(\mathrm{D}) 5 \times 10^{-4} \mathrm{M}:(\mathrm{E}) 5 \times 10^{-3} \mathrm{M}:$ and (F) $5 \times 10^{-2} \mathrm{M}$.

TAPP)(Cl)), deposited on a carbon electrode.

Potentiometric response of the poly(Mn(oTAPP)Cl) electrode toward thiocyanate in a $0.05 \mathrm{M}$ MES buffer, $\mathrm{pH} 5 \cdot 5$, background electrolyte is plotted in Fig. 13. Response time is typically less than $10 \mathrm{~s}$ with detection limits of $5 \times 10^{-6} \mathrm{M}$ $\mathrm{SCN}^{-}$and a slope of $51 \pm 2 \mathrm{mV}$ per decade. There is little deterioration in the slope or detection limit of the calibration curve as a function of time (three weeks) as long as the electrode is not exposed to concentrations of $\mathrm{SCN}^{-}$greater than $1 \times 10^{-2} \mathrm{M}$. These higher concentrations result in positive e.m.f. excursions (drift) which eventually cause the electrode to lose detection and slope with subsequent additions of sodium thiocyanate.

As shown above, poly( $\mathrm{Mn}(o-\mathrm{TAPP}) \mathrm{Cl})$ and poly(Co(o-TAPP)) (Daunert et al., 1991) films exhibit an enhanced selectivity toward thiocyanate. This may be due to differences in the ion-recognition properties of the porphyrin imposed by its immobilization within the electropolymerized matrix. Indeed, the porphyrin monomers are held in the membrane in a threedimensional cross-linked polymerized structure. Such an arrangement should provide an additional control of anion access to axial ligation
TABLE 6 Overall potentiometric response for unconditioned, poly(Mn(o-TAPP)Cl) films in 0.05 M MES, pH 5.5, at $1 \times 10^{-2} \mathrm{M}$ anion concentration ${ }^{a}$

\begin{tabular}{lll}
\hline Anion & $\begin{array}{l}\text { Oxidized film } \\
\text { Change in potential } \\
(\mathrm{mV})\end{array}$ & $\begin{array}{l}\text { Reduced film } \\
\text { Change in potential } \\
(\mathrm{mV})\end{array}$ \\
\hline $\mathrm{I}^{-}$ & -115 & -63 \\
$\mathrm{SCN}^{-}$ & -47 & -177 \\
$\mathrm{ClO}_{4}^{-}$ & -16 & -80 \\
$\mathrm{Sal}^{-b}$ & -42 & -54 \\
$\mathrm{NO}_{3}^{-}$ & -8 & -64 \\
$\mathrm{Br}^{-}$ & -11 & -52 \\
$\mathrm{Cl}^{-}$ & -7 & -33 \\
$\mathrm{HCOO}^{-}$ & -13 & -15 \\
$\mathrm{~F}^{-}$ & -7 & -12 \\
$\mathrm{SO}_{4}^{-2}$ & -5 & -4
\end{tabular}

${ }^{a}$ Films oxidized at $+1.2 \mathrm{~V}$ and reduced at $-0.1 \mathrm{~V}$ vs SSCE for $2 \mathrm{~min}$ following electropolymerization in $\mathrm{CH}_{3} \mathrm{CN}$ and $0.1 \mathrm{M}$ tetraethylammonium perchlorate. ${ }^{b}$ Sodium salicylate.

sites of the central metal ions. This type of molecular sieving property has been confirmed by Pressprich et al. (1989) who obtained permeability data for ultrathin poly( $\mathrm{Co}(o-\mathrm{TAPP}))$ films 


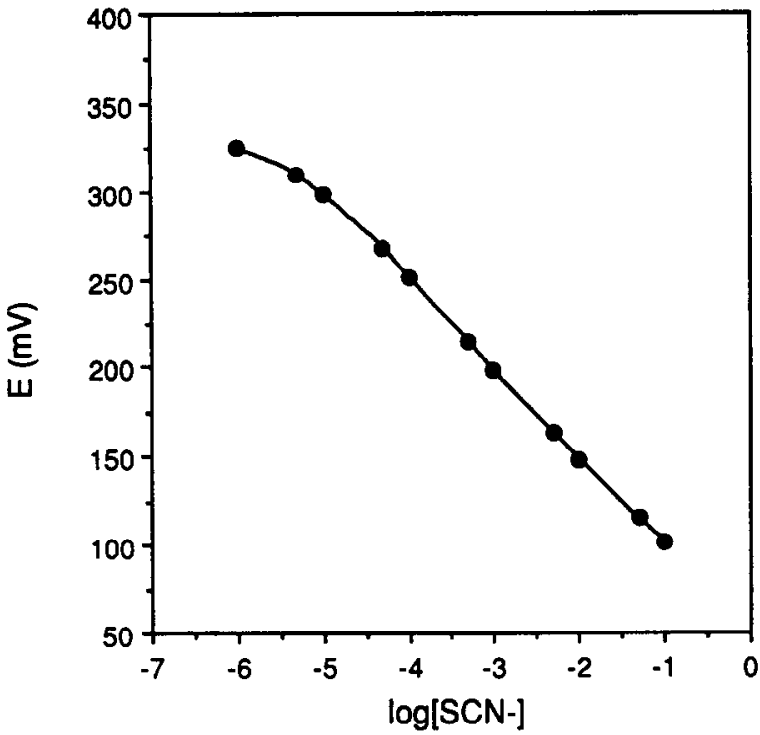

Fig. 13. Typical calibration curve toward $S C N^{-}$for a poly(Mn(o-TAPP)Cl)-modified film electrode in $005 \mathrm{M}$ MES buffer, $p H 5.5$.

to various redox species of different sizes which act as tracers through the film. As a consequence, when using poly(metalloporphyrins) as potentiometric sensor materials, bulkier anions may be precluded (sterically) from an effective interaction with the metal center of the porphyrin. which ultimately leads to enhanced selectivity for small anions (e.g., thiocyanate).

For practical potentiometric anion sensing with such chemically modified film electrodes, it appears that an arrangement must be found that will enable anion permselectivity through the film and not redox chemistry to dominate the potentiometric response. It appears that this may be possible to achieve using reduced films as membranes in conventional ion-selective electrode-type cells. In this regard, special composite porous membranes in which the pores are filled with electropolymerized metalloporphyrins may be useful (Tierney \& Martin, 1990). Research in this direction, using both unmetallated and metallated poly(porphyrin) films as potentiometric sensing materials, is currently in progress within this laboratory.

\section{NEW POTENTIOMETRIC GAS SENSORS}

\subsection{Background}

Over the past two decades ion-selective electrode (ISE)-based potentiometric gas-sensing devices have proven to be attractive analytical tools for the direct detection of dissolved gases (e.g., $\mathrm{NH}_{3}$, $\mathrm{CO}_{2}, \mathrm{NO}_{2}, \mathrm{SO}_{2}$ etc.) in complex samples, including whole blood (Arnold \& Meyerhoff, 1984; Arnold \& Solsky, 1986; Solsky, 1988; Bailey \& Riley, 1975). In addition, when used in conjunction with immobilized enzymes and intact cells, these gas sensors can provide a simple indirect means of quantitating a wide range of biomolecules via modern biosensing configurations (Rechnitz, 1981: Guilbault, 1984; Karube \& Suzuki, 1984).

Currently available commercial gas-sensing membrane electrodes (for $\mathrm{CO}_{2}, \mathrm{NH}_{3}, \mathrm{NO}_{\mathrm{x}}$ etc.) Ross et al., 1973) a re generally based on the design introduced by Severinghaus \& Bradley (1958). In this design, analyte gas diffuses through a gaspermeable membrane (typically silicone rubber or microporous Teflon) into a thin film of electrolyte in contact with a glass membrane $\mathrm{pH}$ electrode. This thin film is also in contact with a bulk volume of the same electrolyte in which the reference half-cell is placed. Within the electrolyte film, the gas participates in an equilibrium reaction with water and the appropriate electrolyte ions. When the partial pressure of gas is equal on both sides of the gas-permeable membrane, an equilibrium $\mathrm{pH}$ value in the thin film is measured by the glass membrane $\mathrm{pH}$ electrode. The resulting signal is logarithmically related to the partial pressure of gas in the sample $\left(P_{\text {gas }}\right)$ according to the Nernst equation

$$
E_{\text {cell }}=K+0.059 \log P_{\text {gas }}
$$

Although effectively used for many years, the Severinghaus-style gas-sensing configuration based on internal glass $\mathrm{pH}$ electrodes has several shortcomings. These include: (a) slow response and long recovery times at low gas concentrations, which severely limit their application in automated gas-sensing instrumentation; (b) poor selectivity over other acidic or basic gases and even non-volatile neutral organic molecules which can diffuse through the outer 'gas'permeable membrane and change the $\mathrm{pH}$ in the internal electrolyte layer; (c) detection limits which are not low enough for certain desirable measurements (e.g., $\mathrm{NH}_{3}$ and $\mathrm{NO}_{x}$ in air); and (d) practical limitations imposed by the use of fragile glass membranes in manufacturing small and inexpensive gas sensors, particularly for in vivo measurements. 


\subsection{Polymer membrane-based gas sensors}

To overcome the problems associated with the Severinghaus-style gas sensors, we have investigated the use of polymeric membrane electrodes as internal transducers in the design of a new generation of gas-sensing devices (Meyerhoff, 1980; Meyerhoff et al., 1982; Martin \& Meyerhoff, 1986; Pranitis \& Meyerhoff, 1989; Opdycke et al., 1983). Figure 14 schematically illustrates this concept for a static gas-sensing configuration. In these new designs, the glass $\mathrm{pH}$ electrode of the conventional gas sensor scheme is replaced with a polymeric membrane sensitive to either $\mathrm{H}^{+}$or an ionic form of the analyte gas (e.g., $\mathrm{NH}_{4}^{+}, \mathrm{CO}_{3}^{2-}$, $\mathrm{NO}_{3}^{-}, \mathrm{HSO}_{3}^{-} / \mathrm{SO}_{3}^{2-}$ etc.). When using polymer membrane $\mathrm{pH}$ electrodes as inner transducers (typically formulated with tridodecylamine as the neutral proton carrier (Opdycke et al., 1983); see compound 8 in Fig. 23 below), issues of selectivity and detection limits remain a concern since the detection process is exactly the same as in the Severinghaus design. However, the resulting gassensing devices are much less expensive to manufacture, are less fragile, and can easily be incorporated into miniaturized devices. Indeed, as described in Section 3.4 below, tubular forms of such polymeric $\mathrm{pH}$ electrodes can be used advantageously in the design of novel in vivo sensors suitable for continuous monitoring of carbon dioxide in blood.

When sensing ionic forms of the analyte gas diffusing through the gas-permeable membrane, the $\mathrm{pH}$ of the recipient solution is held constant by an appropriate buffer. This detection scheme enhances the selectivity of the sensor, since the inner polymeric ion-selective membrane detects only the target ionic form of the gas rather than a

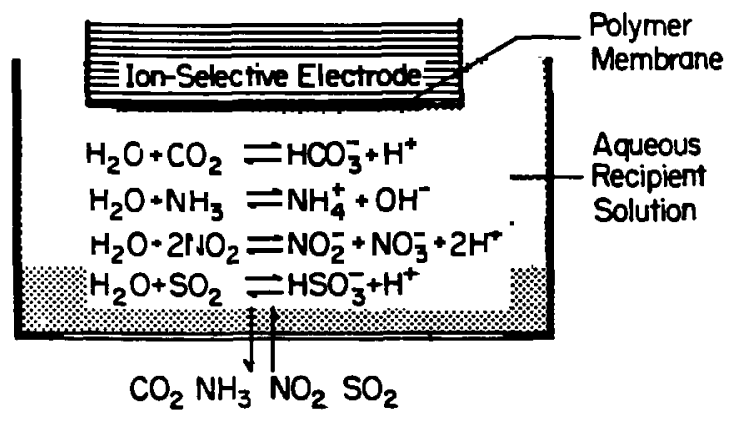

Fig. 14. Concept of using polymer membrane pHorcation/ anion sensor as internal sensing elements for the design of new gas sensors. non-specific change in $\mathrm{pH}$. Consequently, $\mathrm{NH}_{4}^{+}$, $\mathrm{CO}_{3}^{2-}, \mathrm{NO}_{3}^{-}, \mathrm{HSO}_{3}^{-} / \mathrm{SO}_{3}^{2-}$-selective polymer membrane electrodes can serve as internal transducers in more selective and sensitive $\mathrm{NH}_{3}, \mathrm{CO}_{2}$, $\mathrm{NO}_{2}$ and $\mathrm{SO}_{2}$ gas sensors respectively (Meyerhoff, 1980; Meyerhoff et al., 1982; Martin \& Meyerhoff, 1986; Pranitis \& Meyerhoff, 1989).

For example, it is known that conventional ammonia gas sensors which employ an internal $\mathrm{pH}$ glass electrode suffer severe interference from volatile amines because the migration of these species through the outer gas-permeable membrane into the recipient electrolyte layer increases the $\mathrm{pH}$ of the thin electrolyte layer (Fraticelli \& Meyerhoff, 1981). When using an internal ammonium-selective polymer membrane electrode (prepared with the antibiotic nonactin as the membrane active component) in place of the glass $\mathrm{pH}$ electrode, the selectivity of the resulting potentiometric gas sensor is enhanced significantly. Indeed, steady-state potentiometric responses of such a sensor to $\mathrm{NH}_{3}$ and various amines, using $0.2 \mathrm{~mol} \mathrm{l}^{-1}$ Tris- $\mathrm{HCl}, \mathrm{pH} 8.3$, as the internal electrolyte buffer, yield apparent selectivity constants of 0.005 or less, indicating the high degree of selectivity the nonactin membrane has for $\mathrm{NH}_{4}^{+}$over protonated amines (Fraticelli \& Meyerhoff, 1981). Thus, even though the amines diffuse through the gas-permeable membrane, they remain undetected by the internal potentiometric transducer. In addition to this selectivity advantage, the detection capabilities of this system are superior to those of Severinghaus-style sensors. Since the $\mathrm{pH}$ of the electrolyte is fixed, the gas is trapped more efficiently on the recipient side of the membrane. The steady-state concentration of absorbed gas in the thin film is thus significantly increased, resulting in lower detection limits.

The development of novel anion-selective membrane electrodes (such as those described in Section 2) can also lead to the design of improved potentiometric gas-sensing systems. For example, a sulfite-selective polymer membrane electrode prepared with bis(diethyldithiocarbamato)mercury(II) $\left(\mathrm{Hg}(\mathrm{DCC})_{2}\right)$ as the active membrane component has been used as a transducer to devise a new $\mathrm{SO}_{2}$-selective potentiometric gassensing system (Pranitis \& Meyerhoff, 1989). This approach greatly enhances the selectivity for measuring sulfites as $\mathrm{SO}_{2}$ even in the presence of $0.1 \mathrm{M}$ acetic acid. While the acetic acid does permeate through the gas membrane into the 
recipient stream, acetate ions formed in the recipient stream go undetected by the $\mathrm{Hg}(\mathrm{DCC})_{2}-$ based sulfite-selective sensor. This type of enhanced selectivity would be extremely valuable when determining sulfites in wine-vinegar or other samples that contain volatile acidic species. Analogous potentiometric gas-sensing designs for $\mathrm{CO}_{2}$ and $\mathrm{NO}_{x}$ have also been devised in our laboratorics, using carbonate- and nitrateselective polymer membrane electrodes as inner transduction elements (Martin \& Meyerhoff, 1986; Greenberg \& Meyerhoff, 1982).

\subsection{Differential gas sensors}

The polymer membrane electrode-based gas sensors described above each employ a configuration that involves a single working electrode, a suitable reference electrode (usually $\mathrm{Ag} / \mathrm{AgCl}$ ), and an outer gas-permeable membrane. Using polymer membrane electrodes as detectors, however, offers the possibility of designing novel potentiometric gas-sensing devices that use two working electrodes (and no reference) and/or no outer gas-permeable membrane. This is made possible by the lower electrical resistances of carrier-doped polymer membranes relative to glass.

For example, Fig. 15 schematically illustrates a new differential $\mathrm{CO}_{2}$ sensor that can be used to measure $P \mathrm{PO}_{2}$ in undiluted whole blood. Such a probe consists of two identical $\mathrm{pH}$-sensitive membrane electrodes prepared by incorporating tridodecylamine, $o$-nitrophenyloctylether and sodium tetraphenylborate in PVC films. This new sensing design takes advantage of the fact that carbon dioxide readily permeates the protonselective polymer membranes. In this scheme, the internal reference electrolyte buffer of one of the $\mathrm{pH}$ sensors is replaced by a non-buffered bicarbonate electrolyte (e.g., $\mathrm{NaHCO}_{3} / \mathrm{NaCl}$ ). Since $\mathrm{CO}_{2}$ can diffuse through the polymeric ionselective membrane, the $\mathrm{pH}$ of this solution changes as a function of the sample $\mathrm{PCO}_{2}$ level. The second $\mathrm{pH}$ electrode has a strong buffer as its internal reference electrolyte solution, and thus the $\mathrm{pH}$ of this second inner solution does not change as a function of $\mathrm{PCO}_{2}$. If both $\mathrm{pH}$-sensitive polymer membranes are identical in their response to sample (blood) $\mathrm{pH}$, then variations in sample $\mathrm{pH}$ go undetected due to the unique differential measurement arrangement. By carefully evaluating the equations governing the response of each $\mathrm{pH}$ electrode, and by taking into account the equilibrium of $\mathrm{CO}_{2}$ within the inner bicarbonate solution of one of the $\mathrm{pH}$ electrodes, an equation for the overall cell potential can be derived which shows a logarithmic relationship between sample $\mathrm{PCO}_{2}$ and cell e.m.f. with the expected Nernst slope of $59 \mathrm{mV}$ per decade at $25^{\circ} \mathrm{C}$ (see Meyerhoff (1990) for derivation of response equation). This type of differential $\mathrm{PCO}_{2}$ sensor has been shown to function reliably within modern blood gas/electrolyte instruments

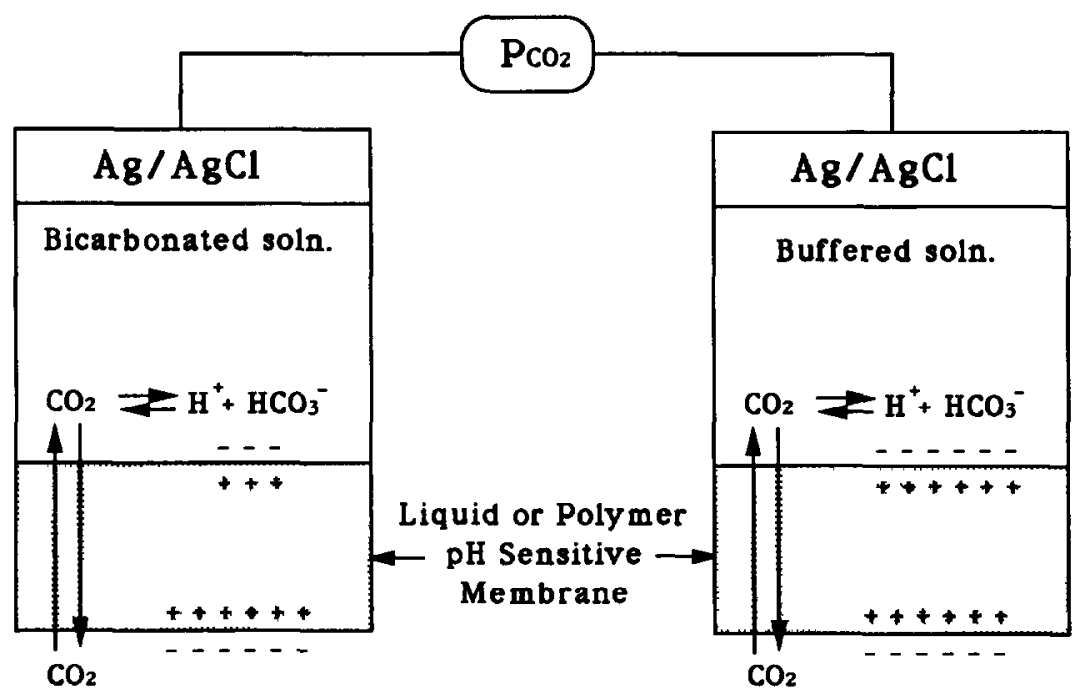

Fig. 15. Schematic diagram of a differential $\mathrm{CO}_{2}$ sensor, based on $\mathrm{pH}$-sensitive polymeric membranes, that can be used to determine $\mathrm{CO}_{2}$ in blood. 
for accurate measurement of $\mathrm{PCO}_{2}$ in wholeblood samples (Meyerhoff, 1980; Strickland et al., 1989 $a, b$; Misiano \& Lowenstein, 1988; Riley, 1987).

Sensitivity can be enhanced with the differential sensor. As with any potentiometric detector used in direct potentiometric measurements (i.e., the non-titration method), conventional Severinghaus-style gas sensors, as well as the newer polymer membrane-based devices cited above, are subject to precision limitations associated with the logarithmic response of such devices. Indeed, uncertainties in measured potentials of $\pm 1 \mathrm{mV}$ will result in analytical concentration uncertainties of $\pm 4 \%$ for sensors with slopes of $59 \mathrm{mV}$ per decade and $\pm 8 \%$ for those devices based on response to divalent ions (e.g., based on inner sulfite and carbonate electrodes).

We recently introduced a rather novel twoelectrode differential potentiometric cell for enzyme electrode systems that provides enhanced substrate sensitivities when compared to conventional cells composed of a single working enzyme electrode and a reference electrode (Cha \& Meyerhoff, 1989b). This concept involves the use of a cell with two working enzyme electrodes, one which responds to the analyte in the positive potential direction via detection of cations, and one which responds to the same analyte but in a negative direction owing to anion detection. This same principle can also be adapted for the design of new two-electrode gas-selective sensors with enhanced sensitivity (as defined by the change in analytical signal/change in concentration; i.e., response slope).

For static configurations, this involves the use of two different gas-sensing half-cell probes where the internal filling solutions are connected via a salt bridge (see Fig. 16) (Yim et al., 1990). One half-cell (b) responds to the basic or acidic analyte gas by detecting an increase or decrease in the $\mathrm{pH}$ of a thin film of electrolyte (e.g., $\mathrm{NH}_{4} \mathrm{Cl}$ for an $\mathrm{NH}_{3}$ gas sensor) sandwiched between a $\mathrm{pH}$-sensitive membrane (prepared with tridodecylamine as membrane active species (Opdycke et al., 1983)) and an outer gas-permeable membrane. The second half-cell (a) detects the analyte gas in the sample by responding to changes in the activities of the conjugate base anion or acid cation (e.g., $\mathbf{N H}_{4}^{+}$for an $\mathbf{N H}_{3}$ gas sensor) of the analyte gas in a thin layer of buffer sandwiched between an ion-selective membrane and another outer gas-permeable film.

Accordingly, in the case of an ammonia gas sensor (Fig. 16), the overall measured potential

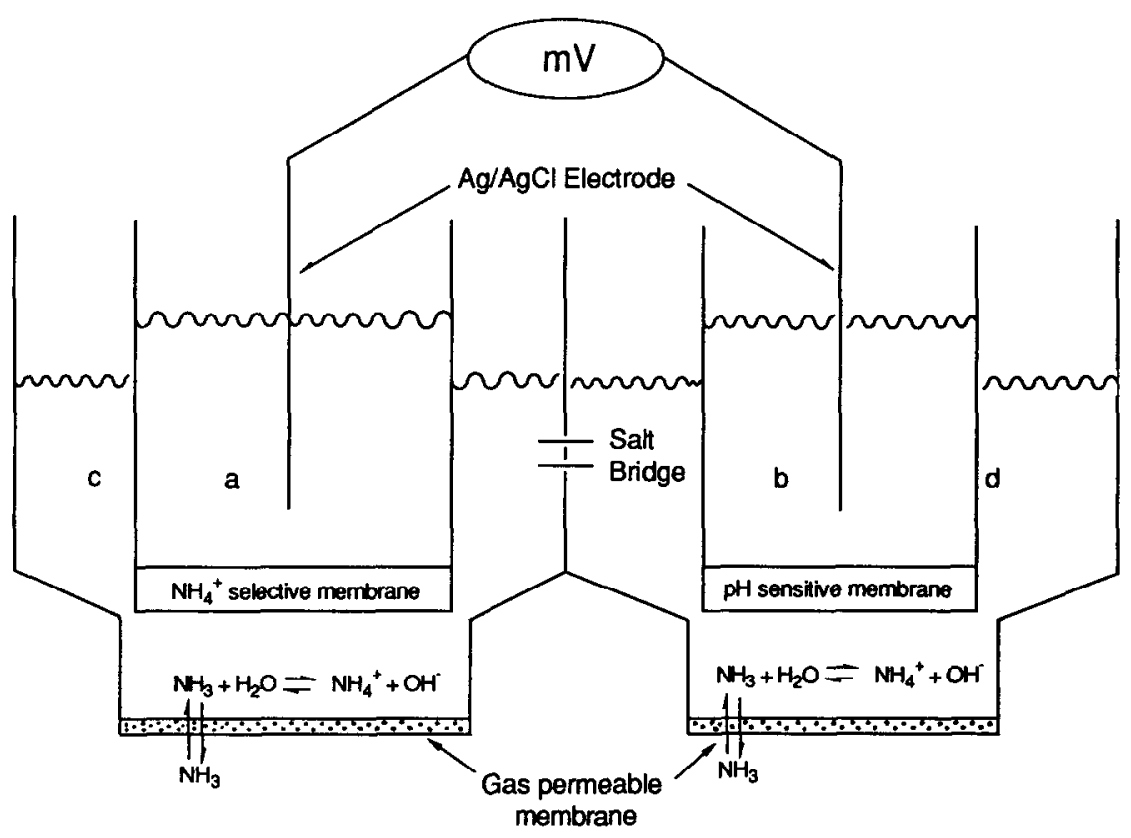

Fig. 16. Schematic diagram of a differential gas sensor fabricated with two different polymeric ion-selective membranes;

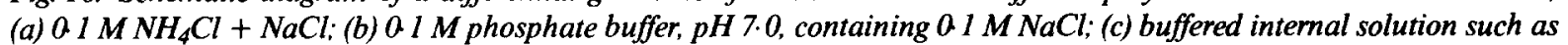
o $1 \mathrm{M}$ Tris- $\mathrm{HCl}$, $\mathrm{pH}$ 7.9; (d) pH-sensing internal electrolyte solution. (From Yim et al. (1990), with permission.) 
for this two-working-electrode cell is the difference in potential between the ammonium ion-selective electrode and the polymeric $\mathrm{pH}$ electrode:

$$
E_{\text {cell }}=E_{\mathrm{NH}_{4}^{+}}-E_{\mathrm{H}^{+}}
$$

or

$$
E_{\text {cell }}=K+0.059 \log a_{\mathrm{NH}_{4}^{+}}-0.059 \log a_{\mathrm{H}^{+}}
$$

where $E_{\text {cell }}$ is in volts, $a_{\mathrm{NH}_{4}^{+}}$and $a_{\mathrm{H}^{+}}$are the activities of ammonium ions and protons in the thin films of internal solutions held between the outer gas-permeable membranes and the respective ion-selective membranes, and $K$ is the sum of all constant potentials in the cell (e.g., junction potentials at salt bridge, inner $\mathrm{Ag} / \mathrm{AgCl}$ potentials of each membrane electrode). Diffusion of gaseous ammonia into the thin films results in the equilibrium hydrolysis of the ammonia:

$$
\mathrm{NH}_{3}+\mathrm{H}_{2} \mathrm{O} \rightleftarrows \mathrm{NH}_{4}^{+}+\mathrm{OH}^{-}
$$

(reaction 1)

with an equilibrium constant of

$$
K_{\mathrm{NH}_{3}}=a_{\mathrm{NH}_{4}^{+}} a_{\mathrm{OH}^{-}} / P \mathrm{NH}_{3}
$$

Therefore, if the $\mathrm{pH}$ of the film in contact with the ammonium electrode is buffered, the $a_{\mathrm{NH}_{4}^{+}}$in the film is directly proportional to the partial pressure of ammonia gas:

$$
a_{\mathrm{NH}_{4}^{+}}=P \mathrm{NH}_{3} K_{\mathrm{NH}_{3}} / a_{\mathrm{OH}^{-}}
$$

On the other hand, for the $\mathrm{pH}$ electrode half-cell, since $a_{\mathrm{OH}^{-}}=K_{\mathrm{w}} / a_{\mathrm{H}^{+}}$, then the activity of protons in the thin film is given by

$$
a_{\mathrm{H}^{+}}=a_{\mathrm{NH}_{4}^{+}} K_{\mathrm{w}} / P \mathrm{NH}_{3} K_{\mathrm{NH}_{3}}
$$

However, in the pH half-cell, $a_{\mathrm{NH}_{4}^{+}}$is kept high and relatively constant by using $\mathrm{NH}_{4} \mathrm{Cl}$ as the thin film electrolyte. Thus, substituting equations (9) and (10) into equation (7) and combining all the constant terms together yields the following expression for the overall differential cell potential:

$$
E_{\text {cell }}=K^{\prime}+0.118 \log P \mathrm{NH}_{3}
$$

As can be seen, such a cell should respond to the partial pressure of ammonia with a theoretical slope of $118 \mathrm{mV}$ per decade. The ammoniasensing arrangement serves as a convenient model since, as stated previously, the required $\mathrm{NH}_{4}^{+}$-selective membrane can be readily prepared by incorporating the antibiotic nonactin into a plasticized PVC membrane (Meyerhoff, 1980), and the $\mathrm{pH}$ electrode can be fabricated with a PVC membrane doped with tridodecylamine.

For three separate experiments, the average slope of the new static sensor's differential ammonia response was found to be $96.3 \pm 0.5 \mathrm{mV}$ per decade in the range of $10^{-6}$ to $10^{-3} \mathrm{M} \mathrm{NH}_{3}$. This slope is somewhat less than the theoretical value of $118 \mathrm{mV}$ per decade predicted using the simplified model described above. This difference is expected in the case of the static sensor configuration for a number of practical reasons outlined elsewhere (Yim etal., 1990; Meyerhoff et al., 1983); for example, the polymeric $\mathrm{pH}^{-}$and ammonium-selective membranes used in each half-cell typically exhibit sub-Nernstian slopes of 54-58 $\mathrm{mV}$ per decade even when used as independent ion sensors under equilibrium conditions.

Using two gas dialysis cells and flow-through ammonium and $\mathrm{pH}$ polymeric membrane electrodes, a similar differential detection system with enhanced sensitivity can be devised to quantitate ammonia in a continuous flowthrough arrangement (Yim et al., 1990). Such a system has been used successfully to determine the ammonia-N content (total dissolved ammonia gas plus ammonium ions) of media samples obtained from bioreactors used to produce monoclonal antibodies.

Ammonia- $\mathrm{N}$ values determined with the flowthrough differential ammonia detector correlated well with both a manual commercial ammonia electrode procedure $(r=0.981)$ and a conventional enzymatic method $(r=0.938)$. It is known that elevated levels of a mmonia- $\mathrm{N}$ in such culture media can inhibit hybridoma cell growth (Glacken etal., 1986), and thus routine monitoring of ammonia- $\mathrm{N}$ along with key nutrients (e.g., glucose and glutamine) is becoming increasingly more important in such biotechnology processes.

In principle, the concept of enhancing slopes for potentiometric gas sensing can be applied to a large number of analyte gases. In some instances, the required polymer membrane electrodes with suitable selectivity have already been described in the literature. For example, it should be possible to design an $\mathrm{SO}_{2}$-sensitive differential cell with enhanced gas sensitivity by detecting bisulfite/sulfite from diffusing $\mathrm{SO}_{2}$ in one halfcell (using the $\mathrm{Hg}$ (II)-based polymer membrane 
electrode for sulfite (Pranitis \& Meyerhoff, 1989)) and a $\mathrm{pH}$ change in the other. Similarly, detectors for $\mathrm{NO}_{2}$ could be devised by employing either a nitrate- or a nitrite-selective polymer membrane electrode in conjunction with an appropriate internal or flowing recipient buffer reagent in one half-cell, and nitrite solutions along with a $\mathrm{pH}$ sensor in the other. In all cases, a significant enhancement in the response slope compared to existing gas-sensing arrangements should be realized.

\subsection{Gas/ion-sensing catheters for in vivo monitoring}

Polymer membrane electrode technology can also offer exciting possibilities for the development of implantable sensors. Indeed, the development of biomedical devices capable of continuous in vivo monitoring of blood gases. electrolytes and certain metabolites would have the inherent advantage of providing real-time information about a patient's respiratory and metabolic state. This is in contrast to the conventional approach, where the analysis of discrete blood samples at laboratories remote from the patient's bedside results in delays that may prevent the early detection of changing blood chemistries in unstable patients. The analytical errors induced by the required sample transport process are also a major concern. All of this may hinder the accurate diagnosis and timely intervention in critically ill patients. In this section, we summarize our recent efforts to develop inexpensive, rugged and simple polymer membrane-based electrochemical sensors for in vivo gas/ion monitoring.

One of our early developments was a potentiometric $\mathrm{PCO}_{2}$-sensing catheter based on an internal tubular polymer $\mathrm{pH}$ electrode in conjunction with an outer gas-permeable silicone rubber tube (Opdycke \& Meyerhoff, 1986). Figure 17(a) schematically illustrates the unique concentric tubular geometry of this sensor, in which the polymeric $\mathrm{pH}$-sensitive membrane is safely situated within the wall of the internal tubing and not at the tip. This prevents damage of the sensing region during intravascular catheter placement or removal. With this design. sensor size reduction can be achieved without a corres-

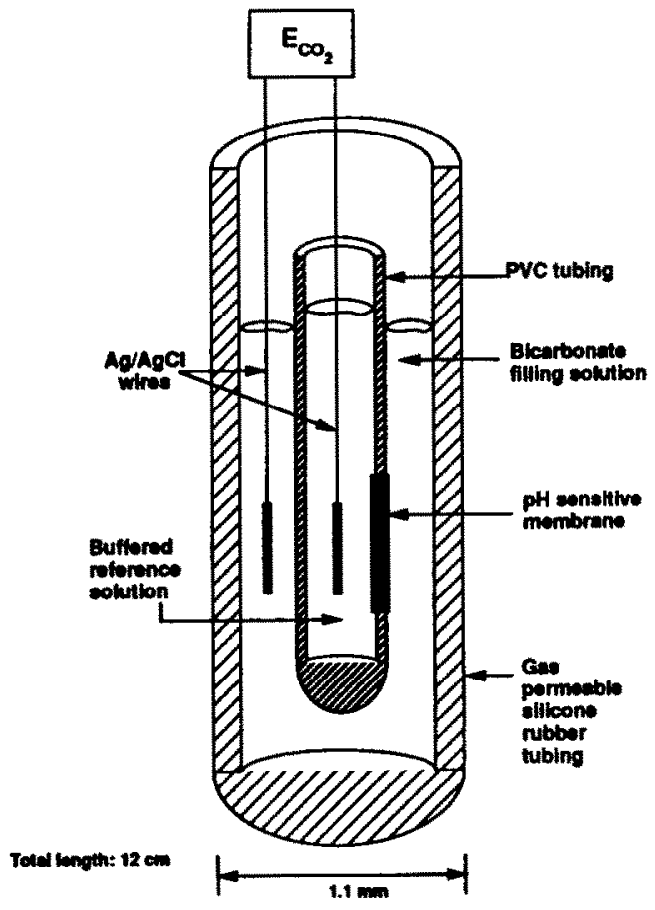

(a)

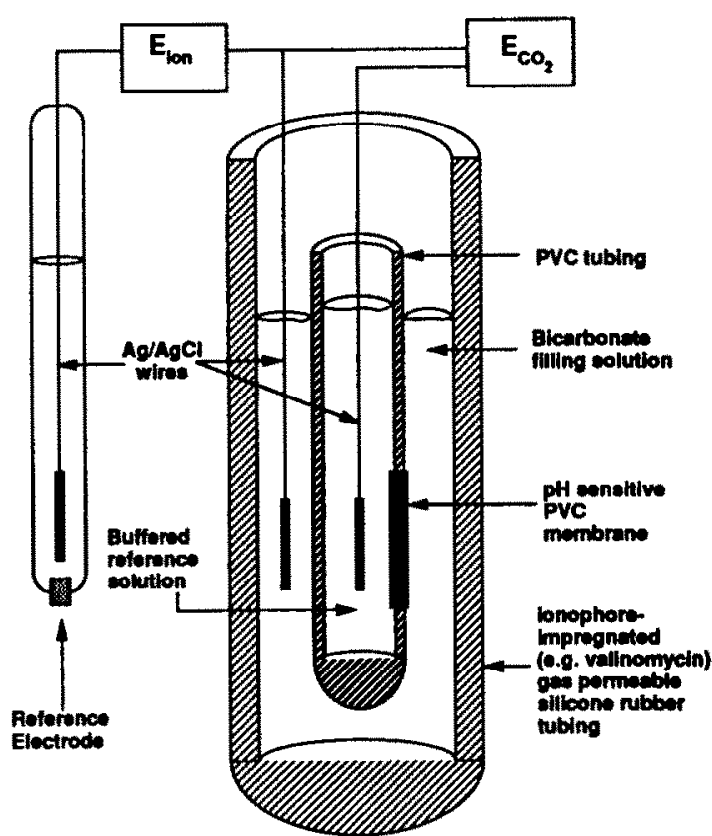

(b)

Fig. 17. Schematic diagrams of (a) tubular polymer membrane electrode-based $\mathrm{PCO}_{2}$ catheter and (b) dual ion/ $P C \mathrm{O}_{2}$ catheter configured as a $\mathrm{K}^{+} / \mathrm{PCO}_{2}$ sensor. 
ponding decrease in the $\mathrm{pH}$-sensitive membrane and a concomitant increase in electrode resistance. The tubular $\mathrm{CO}_{2}$ sensor functions in a manner analogous to the conventional Severinghaus design. Carbon dioxide diffuses through the wall of the outer silicone rubber tube, changing the $\mathrm{pH}$ of the electrolyte solution which fills this outer tube. The inner tubular $\mathrm{pH}$ electrode monitors this change. Although $\mathrm{CO}_{2}$ can also permeate the walls of this inner tubular $\mathrm{pH}$ electrode, the internal solution of this tube is strongly buffered to prevent a $\mathrm{pH}$ change that would offset the response at the outer surface of the inner probe.

This $\mathrm{PCO}_{2}$ catheter design can be further modified to devise a novel dual ion/ $\mathrm{PCO}_{2}$-sensing configuration (Collison et al., 1989). As an initial model, a potassium/ $/ \mathrm{PCO}_{2}$ sensing probe (Fig. 17(b)) has been prepared by impregnating the outer silicone gas-permeable membrane of the $\mathrm{PCO}_{2}$ catheter with the potassium ionophore, valinomycin. The sample potassium activity is monitored by measuring the potential across the wall of the outer ion-selective, gas-permeable silicone tubing. Simultaneously, the sample $\mathrm{PCO}_{2}$ is monitored by measuring the potential across the inner tube containing the $\mathrm{pH}$-sensitive membrane. This design can be also adapted to determine ions other than potassium (e.g. $\mathrm{Ca}^{2+}$, $\mathrm{Na}^{+}$) by incorporating the appropriate ionophore into the wall of the outer $\mathrm{CO}_{2}$-permeable tubing.

The required external reference electrode for the ion measurement can be, for in vitro blood testing, any standard junctioned reference electrode. For in vivo studies, the reference electrode/catheter guide assembly depicted in Fig. 18 has been employed. This implant assembly consists of a 14-gauge catheter guide, a Y-adapter and an external $\mathrm{Ag} / \mathrm{AgCl}$ reference electrode. The external reference electrode, housed in a PVC tube and containing an electrolyte gel, is separated from the sample by a $1000 \mathrm{MW}$ cutoff cellulose dialysis membrane. Electrical contact between the reference electrode and the ion-responsive region of the implanted sensor is made by a normal saline drip solution containing heparin.

In vivo evaluation of the $\mathrm{K}^{+} / \mathrm{PCO}_{2}$ levels, using the catheter assembly in anesthetized, systemically heparinized dogs, correlated well with discrete sample values measured on conventional blood gas-electrolyte analyzers. Figure 19 illustrates the results obtained for one such study. It is important to note, however, that in the absence of systemic heparinization, the formation of blood clots at

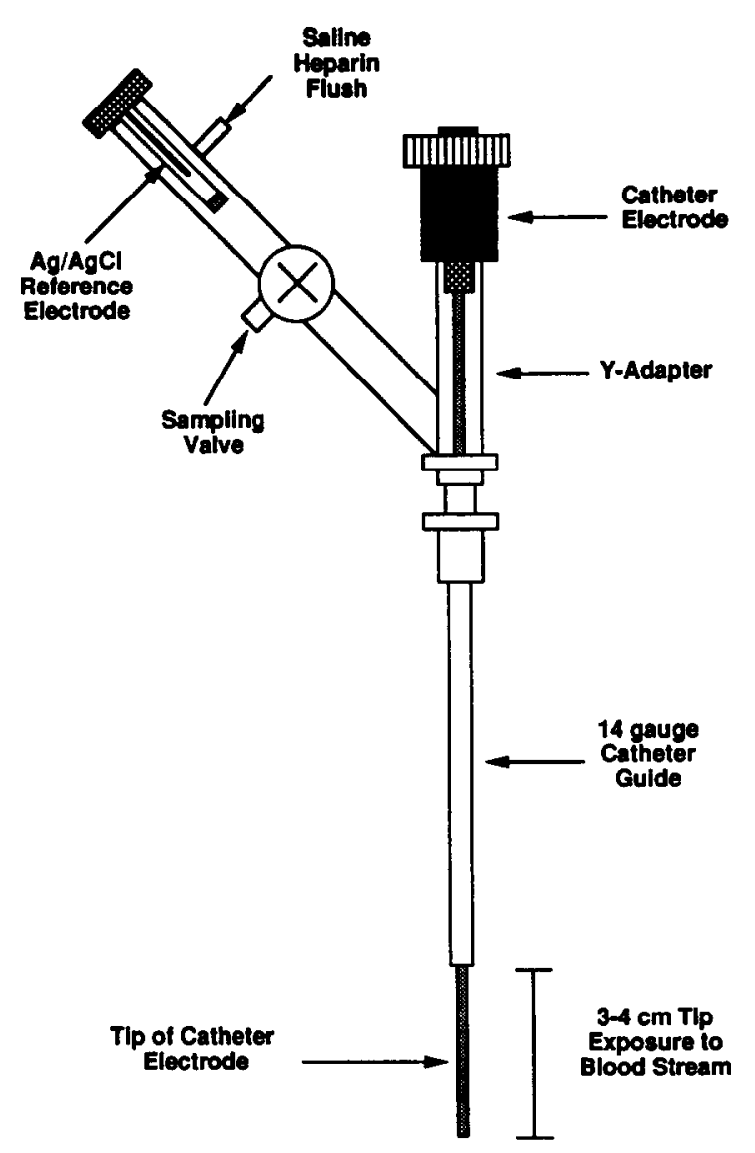

Fig. 18. Catheter implant assembly used for in vivo studies. (From Collison et al. (1989), with permission.)

the surface of the sensor can lead to large discrepancies between catheter and in vitro instrumental values. Such discrepancies are due to a biocatalytic activity within the thrombus that alters the values of gases and ions (particularly $\left.\left[\mathrm{H}^{+}\right]\right)$at the surface of the implanted probe, and not to fouling of the sensor. Current efforts in this laboratory are focusing on ways to render the surfaces of such polymeric catheters less thrombogenic without compromising analytical performance. This includes use of antithrombogenic drugs that slowly release from the outer ionselective tubing, and studies of more biocompatible polymeric tubing materials that can be doped with appropriate ionophore reagents for catheter fabrication.

Another novel design for ion/gas sensing employs a dual lumen configuration (Collison \& Meyerhoff, 1989) rather than a concentric arrangement. As shown in Fig. 20, an entire segment of dual lumen silicone rubber tubing can be impregnated with the hydrogen ionophore 

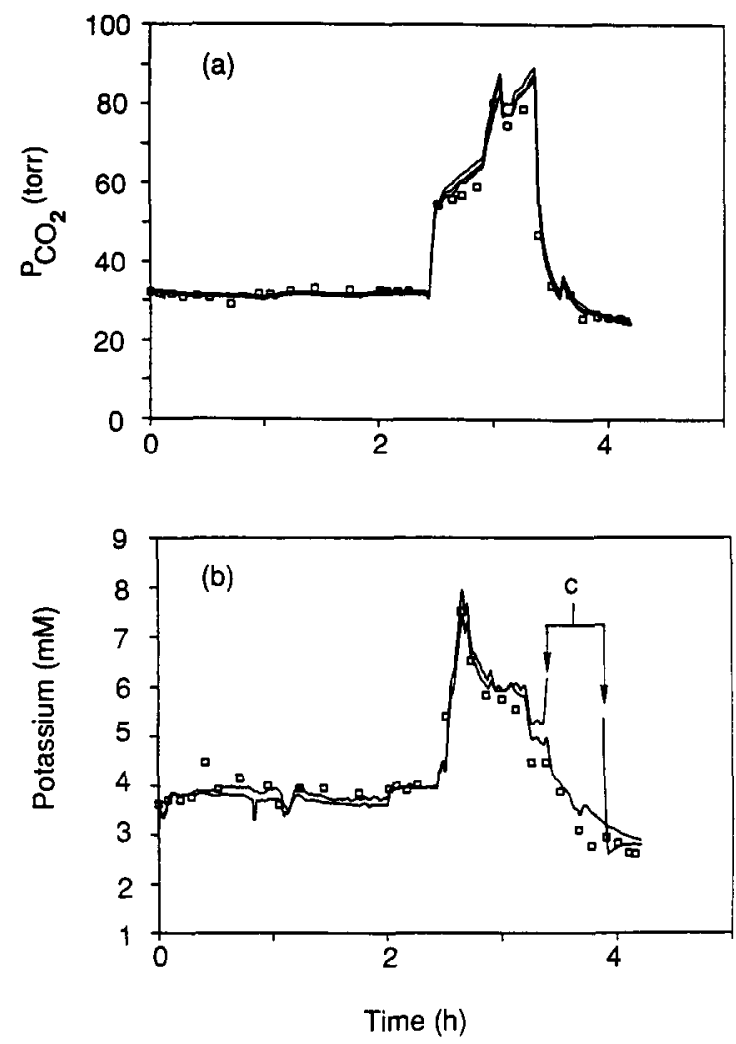

Fig. 19. Continuous response of two combination catheter sensors toward (a) $\mathrm{CO}_{2}$ and (b) $\mathrm{K}^{+}$during in vivo measurements (in dog) with continuous heparin infusion. In vitro values ( $\square$ ); $c$ denotes errant values that resulted from blood contamination of the catheter reference electrode for one of the implants. (From Collison et al. (1989), with permission.)

tridodecylamine, which imparts $\mathrm{H}^{+}$ion permselectivity to all inner and outer walls of the tubing. When one lumen is filled with a strong buffer and the other with a bicarbonate $/ \mathrm{NaCl}$ solution, the electrochemical potential between the two lumens (measured with the use of two $\mathrm{Ag}$ / $\mathrm{AgCl}$ reference wires) is proportional to the logarithm of $\mathrm{PCO}_{2}$ in the solution bathing the catheter. This design offers the advantage of reduced fabrication complexity (i.e., no tubewithin-a-tube arrangement) and thus greater potential for sensor miniaturization. Furthermore, simultaneous monitoring of sample $\mathrm{pH}$ and $\mathrm{PCO}_{2}$ can be accomplished by contacting the sample with an external reference electrode and measuring the difference in potential between this external reference and the lumen containing the strong buffer. Such a design is currently being evaluated in vivo.

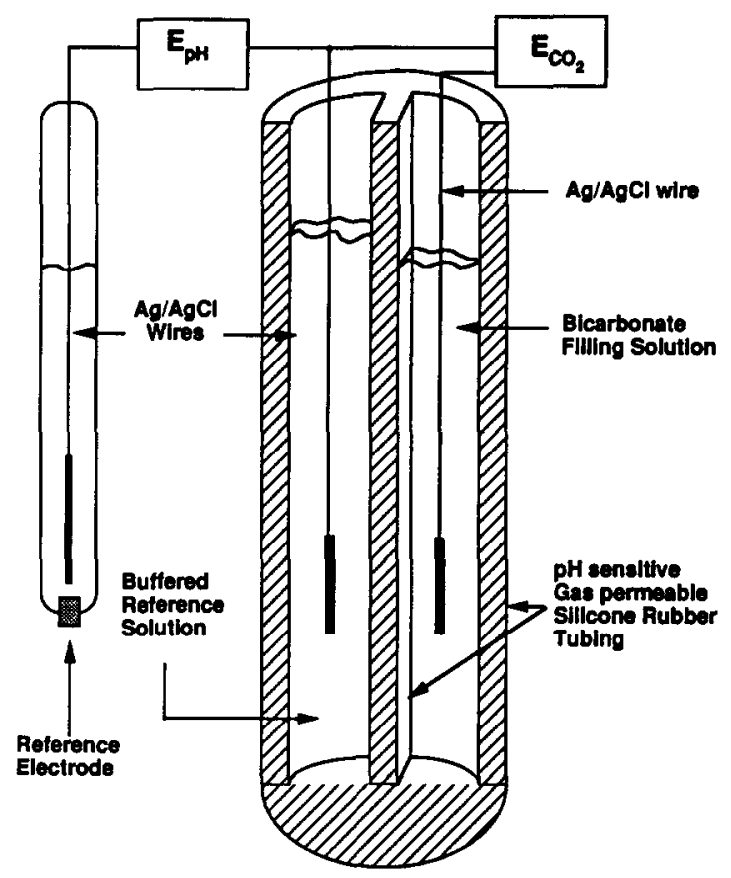

Fig. 20. Representation of novel dual-lumen combination $p H / P_{\mathrm{CO}_{2}}$ catheter.

\subsection{Potentiometric oxygen sensors}

One biologically important gas that, until recently, could not be measured by potentiometric methods is oxygen. Indeed, almost all biomedical measurements of dissolved oxygen are made with an amperometric Clark-style oxygen probe (Clark, 1956). In this design, oxygen diffuses through a gas-permeable membrane and is reduced at a platinum cathode polarized at -0.6 to $-0.8 \mathrm{~V}$ vs. an $\mathrm{Ag} / \mathrm{AgCl}$ reference. The resultant current flow is linearly related to dissolved oxygen in the sample. Changes in membrane permeability, cathode surface area etc. cause considerable drift in sensor response, and this has hampered efforts to implement this sensor for continuous in vivo measurements of $\mathrm{PO}_{2}$. An equilibrium-type potentiometric sensor could offer advantages in terms of long-term stability, etc., and thus efforts to devise such a probe seem worthwhile, both in terms of fundamental science and of potential bioanalytical applications.

Our initial work toward this goal has been to study the potentiometric oxygen response of platinum electrodes coated with polymeric films that contain lipophilic metal-ligand complexes that bind oxygen reversibly at room temperature. The literature describes a wide range of such 
species, including $\mathrm{Fe}(\mathrm{II}), \mathrm{Ru}(\mathrm{II})$ or $\mathrm{Co}(\mathrm{II})$ metalloporphyrins, Co(II)-polyamines, and Schiff-base complexes of Co(II) (McLendon \& Martell, 1976; Niederhoffer et al., 1984; Jones et al., 1979). All of these dioxygen ligated complexes, however, eventually undergo irreversible degradation reactions to form inert complexes that have no affinity for dioxygen. Nonetheless, if the reversible binding reaction can proceed for a reasonable time, it is possible to measure a reversible change in the redox potential of the metal-ligand complex as a function of the partial pressure of oxygen present. At the same time, the use of a polymeric matrix, as opposed to an aqueous or non-aqueous electrolyte solution, could offer the advantage of decreasing the rate of oxidation of the complex, thus increasing sensor lifetime.

As an initial model system, platinum electrodes were coated with PVC membranes containing $\mathrm{Co}$ (II)-tetren (tetraethylenepentamine) oxygenbinding complexes (Yim \& Meyerhoff, 1992) and the potentiometric response of the coated electrodes toward oxygen was assessed. Figure 21 shows the typical tracings for the response of such an electrode to oxygen in a $50 \mathrm{mmol} \mathrm{l}^{-1} \mathrm{MES}$ buffer, $\mathrm{pH} 5 \cdot 5$, at $24^{\circ} \mathrm{C}$ on the first day, and 8 days after preparation. It is clear that over this period of time the response to oxygen is significant and reversible. The magnitude of response, particularly at low concentrations of oxygen, decreases with time, while the absolute potential of the cell drifts more positive over this same time period. This is shown more clearly in Fig. 22 which illustrates the absolute cell potentials vs. the logarithm of percentage oxygen concentration over an 8-day period for Pt electrodes coated with Co(II)-tetren-doped polymer films.

The absolute cell potential measured for this sensing system can be expressed as

$$
E_{\text {cell }}=E_{\text {work }}-E_{\text {ref }}
$$

where $E_{\text {work }}$ is the potential of the platinum electrode coated with the Co(II)-tetren/PVC film, and $E_{\text {ref }}$ is the potential of the external reference electrode. If it is assumed that the potential of the working platinum electrode is poised solely by an electrochemically reversible $\mathrm{Co}(\mathrm{III}) / \mathrm{Co}(\mathrm{II})$ tetren complex redox couple within the polymer film, and that the Co(II)-tetren binds oxygen reversibly according to the following reaction
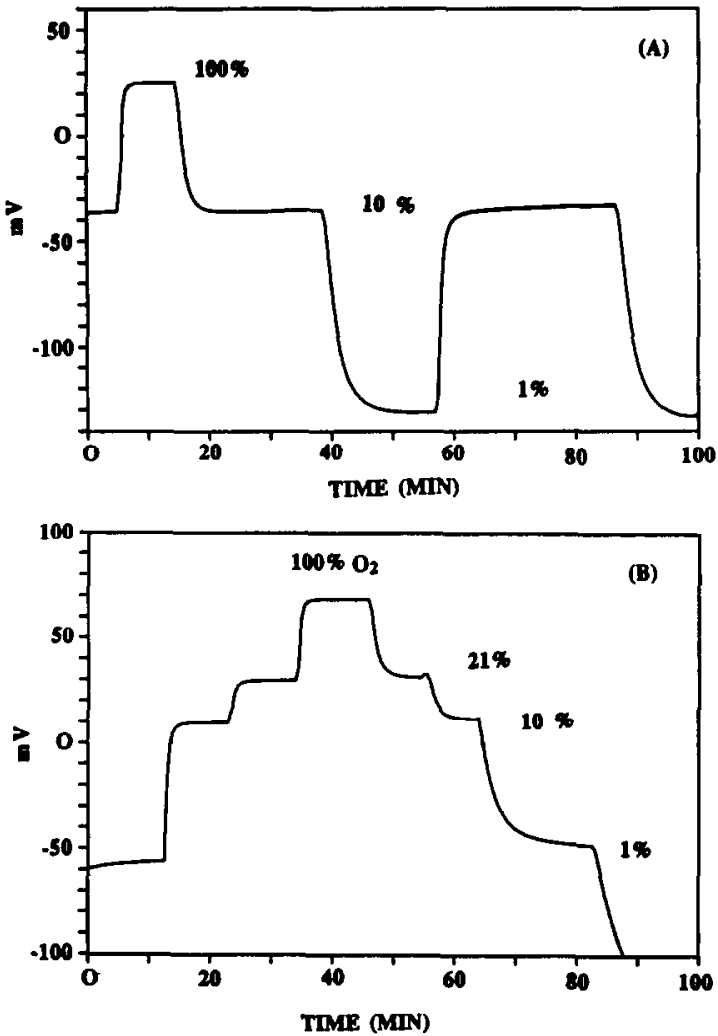

Fig. 21. Dynamic response of Co(II)-tetren/PVC polymeric membrane-based oxygen sensor in a $50 \mathrm{mM} M E S$ buffer, pH 5. 5, at $24^{\circ} \mathrm{C}$ on the Ist $(A)$ and 8th (B) days. (From Yim \& Meyerhoff (1992), with permission.)

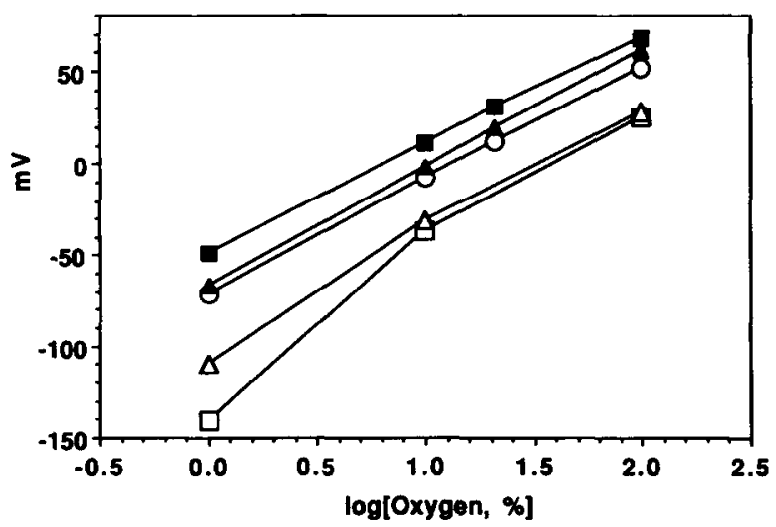

Fig. 22. Calibration curves for a Co(II)-tetren/PVC-based oxygen sensor over 8 days in a $50 \mathrm{mMMES}$ buffer, pH 5.5 ,

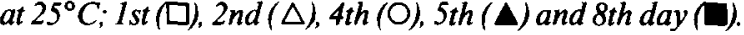

(From Yim \& Meyerhoff (1992), with permission.)

$$
\mathrm{L}_{5} \mathrm{Co}(\mathrm{II})+\mathrm{O}_{2} \rightleftarrows \mathrm{L}_{5} \mathrm{Co}(\mathrm{III})-\mathrm{O}_{2}^{-}
$$

(reaction 2)

with an equilibrium constant expressed as

$$
K_{\text {eq }}=\left[\mathrm{L}_{5} \mathrm{Co}(\mathrm{III})-\mathrm{O}_{2}^{-}\right] /\left[\mathrm{L}_{5} \mathrm{Co}(\mathrm{II})\right] \mathrm{PO}_{2}
$$


then,

$$
\begin{gathered}
E_{\text {cell }}=K+(R T / n F) \ln \left(\left[\mathrm{L}_{5} \mathrm{Co}(\mathrm{III})-\mathrm{O}_{2}^{-}\right] /\right. \\
\left.\left[\mathrm{L}_{5} \mathrm{Co}(\mathrm{II})\right]\right)
\end{gathered}
$$

where $K$ is the cell constant (potential of reference electrode in this case), $\mathrm{L}$ represents the nitrogen ligands of the tetren molecules, and $\mathrm{PO}_{2}$ is the partial pressure of oxygen. If a cobalt complex in the membrane has a 1:1 stoichiometry with a molecular oxygen in the polymeric film, then, by rearranging eqn. (13) and substituting into eqn. (14), $E_{\text {cell }}$ can be related to the partial pressure of oxygen by the following expression:

$$
E_{\text {cell }}=K+(R T / n F) \ln \left(P \mathrm{O}_{2(\text { sol })} K_{\text {eq }}\right)
$$

Since $K_{\text {eq }}$ is constant, then

$$
E_{\text {cell }}=K^{\prime}+0.059 \log P_{2}
$$

While the theory predicts a Nernstian slope of $59 \mathrm{mV}$ per decade, sensors prepared with the $\mathrm{Co}(\mathrm{II})$-tetren complex/PVC film consistently yield much higher slopes, particularly in the range below $10 \%$ oxygen, over the first few days of operation (see Fig. 22). The origin of these higher slopes appears to be due to a concomitant response of the underlying platinum electrode toward oxygen that permeates the PVC film. This additive response is dependent on the surface state of the electrode (i.e., the reduced platinum surface yields significant potentiometric oxygen response in aqueous solution) (Yim \& Meyerhoff, 1992). Nonetheless, in the presence of the Co(II)tetren/PVC film, an analytically useful response is observed for about 6-8 days (see Figs. 21, 22) and this is considerably longer than that observed for fully reduced bare platinum electrodes. After this point, the degradation of the $\mathrm{Co}$ (II)-tetren complex, coupled with the oxidation of the underlying platinum surface, results in very slow and irreversible responses toward oxygen.

The interface of the Co(II)-tetren/PVC film and the sample solution also develops a phaseboundary potential that is dependent on sample $\mathrm{pH}$ and anion activities. This potential adds on to the measured cell potential. Thus, for practical analytical measurements of $\mathrm{PO}_{2}$, the $\mathrm{Co}$ (II)tetren/PVC membrane-coated platinum electrodes (and reference half-cell) must be placed behind an additional outer gas-permeable membrane so that variations in sample anion activities and $\mathrm{pH}$ do not influence the measured cell potential. Work on devising such practical potentiometric oxygen gas sensors is currently under way, as are efforts to use alternative metal-ligand complexes that may exhibit enhanced stability within the polymeric membrane.

\section{POLYMER MEMBRANE-BASED BIOSENSORS}

\subsection{Novel polymer membrane materials for ion sensors and biosensors}

Moving towards our goal of developing clinically useful sensors that can be classified as true biosensors, we have directed part of our research efforts into optimizing the union of enzyme and immuno-techniques with potentiometric polymer membrane ion-sensing configurations. Indeed, certain polymer membrane-type ion sensors can serve as very attractive base transducers for the preparation of potentiometric biocatalytic- and immuno-biosensors. In fact. some of the earliest potentiometric enzyme electrodes were fabricated with these types of electrode (Carr \& Bowers, 1980; Guilbault. 1976). In particular, polymer membrane ion-selective electrodes for $\mathrm{pH}$, ammonium and carbonate can be coupled with various enzyme and immuno-enzyme systems to generate a wide range of devices suitable for bioanalytical measurements. This is because there are a large number of enzymes that either generate acid/base products or liberate ammonia or carbon dioxide (so-called deaminase and decarboxylases). Polymer membrane electrodes selective for these product ions or gases can be prepared by doping membranes with the structures illustrated in Fig. 23 (nonactin, 7 , for ammonium sensing; tridodecylamine, $\underline{8}$, for $\mathrm{pH}$ sensing; and trifluoro-p-butylbenzene, $\underline{9}$, for carbonate sensing). These are the same ionophores that have also been employed in the fabrication of several of the new gas sensing schemes described above (Section 3).

While enzymes and antibodies can be deposited on the surface of PVC membranes doped with these species, typically by crosslinking the bioreagents with glutaraldehyde (Carr \& Bowers, 1980), such immobilized protein layers generally have poor adhesion to the very hydrophobic surface of the plasticized PVC membranes. At the same time, plasticized PVC membranes have poor adhesion to silicon dioxide and silicon nitride substrate materials that are potentially 


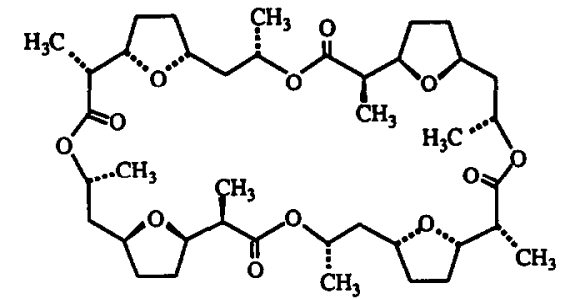

$\underline{7}$

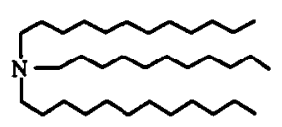

$\underline{8}$

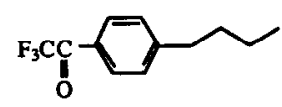

2
Fig. 23. Structures of nonactin (7). tridodecylamine (8) (TDDA) and trifluoro-p-butylbenzene (9) used to prepare ammonium, $\mathrm{pH}$ and carbonate selective polymer membrane electrodes.

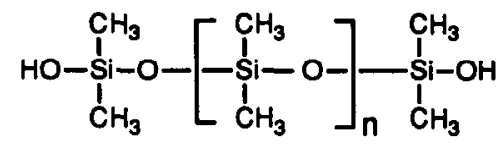

Polydimethylsiloxane, Silanol Terminated

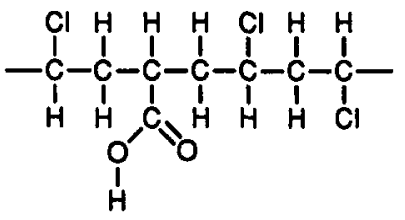

Carboxylated-PVC (COOH-PVC) useful in the fabrication of microelectronic-type ion sensors and biosensors (see Section 4.4 below). For these reasons, we have had a long-term interest in assessing the use of alternative polymer matrices (other than PVC) to prepare polymer membrane-type ion-selective electrodes (Ma et al., 1988; Cha et al., 1991). Ideally, such matrices should include functional groups on the polymer backbones that would enable covalent attachment of bioreagents, and/or better adhesion of such membranes to solid-state surfaces. Figure 24 illustrates some of the polymer structures we have investigated in recent years. Clearly, in order for these materials to be useful in biosensor or microelectronic fabricated sensor work, it is essential that the electrochemical performance of the resulting ionophore-doped membranes be equivalent to those prepared with conventional

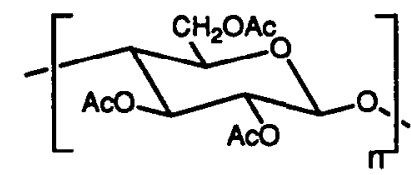

Cellulose Triacetate (CTA)<smiles>CC(Cl)CC(Cl)CC(C)Cl</smiles>

Aminated-PVC $\left(\mathrm{NH}_{2}-\mathrm{PVC}\right)$<smiles>CC(=O)OCC(C)CCl</smiles>

Vinyl Chloride/Ninyl AcotateNinyl Alcohol Copolymer (PVA)

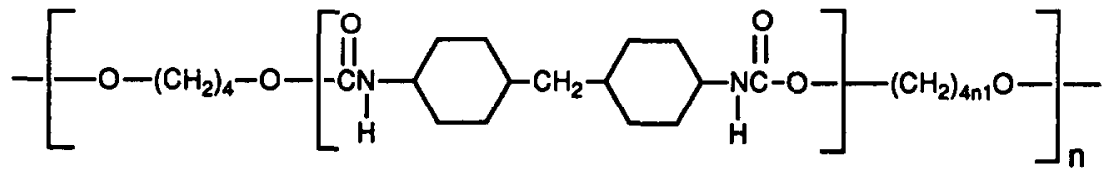

Tecoflex Polyurethane (PU)

Fig. 24. Structures of various polymer matrices examined for preparing potentiometric ion- or bio-sensors. 
TABLE 7 Selectivity coefficients of nonactin-based membranes prepared with various polymer matrices

\begin{tabular}{|c|c|c|c|c|c|c|c|c|}
\hline \multirow{2}{*}{$\begin{array}{l}\text { Membrane } \\
\text { matrix }^{b}\end{array}$} & \multirow[t]{2}{*}{ Plasticizer } & \multicolumn{7}{|c|}{$\log \mathrm{K}_{\mathrm{NH}_{4}^{+} \text {pota }}$} \\
\hline & & $\mathrm{Li}^{+}$ & $\mathrm{Na}^{+}$ & $\mathrm{K}^{+}$ & $\mathrm{Mg}^{2+}$ & $\mathrm{Ca}^{2+}$ & $\mathrm{Me}_{4} \mathrm{~N}^{+}$ & $\mathbf{H}^{+}$ \\
\hline PVC & dibutyl sebacate & $-4 \cdot 5$ & -2.9 & -0.9 & -2.9 & $-5 \cdot 0$ & $-3 \cdot 7$ & -5.0 \\
\hline $\mathrm{COOH}-\mathrm{PVC}$ & dibutyl sebacate & -4.0 & -2.7 & -0.8 & $-2 \cdot 9$ & $-4 \cdot 8$ & $-3 \cdot 7$ & $-4 \cdot 5$ \\
\hline $\mathrm{NH}_{2}-\mathrm{PVC}$ & dibutyl sebacate & $<-4.0$ & -2.7 & -0.8 & $-2 \cdot 8$ & $<-4.0$ & $<-3.6$ & $<-3.9$ \\
\hline CTA & dipentyl phthalate & -4.7 & -2.9 & -0.9 & $-3 \cdot 2$ & $-5 \cdot 0$ & $-3 \cdot 7$ & $-4 \cdot 3$ \\
\hline PU/PVA & dioctyl sebacate & -4.8 & $-3 \cdot 2$ & -1.2 & -4.7 & $-4 \cdot 7$ & -40 & -4.4 \\
\hline
\end{tabular}

${ }^{a}$ Determined by the separate solution method.

${ }^{b}$ PVC: poly(vinyl chloride); $\mathrm{COOH}-\mathrm{PVC}$ : carboxylated poly(vinyl chloride); $\mathrm{NH}_{2}-\mathrm{PVC}$ : aminated poly(vinyl chloride); CTA: cellulose triacetate; PU/PVA: polyurethane (Tecoflex)/(vinyl chloride/ vinyl acetate/vinyl alcohol, 80/5/15 wt\%).

PVC, in terms of ion selectivity, response slope, etc.

Table 7 summarizes potentiometric selectivity data for ammonium-selective membrane electrodes prepared with some of the polymers shown in Fig. 24. In all cases $1 \mathrm{wt} \%$ of nonactin was doped into the plasticized polymer films. The PU/PVA membrane refers to one that contained an 80:20 (wt\%) mixture of Tecoflex polyurethane (PU) and the terpolymer of vinylchloride/vinylacetate/ vinylalcohol (PVA). As can be seen, for each of the polymers tested, the potentiometric selectivity for ammonium ions over a wide range of other cations is quite similar to that obtained with the conventional PVC matrix. In addition, the detection limits and response time toward ammonium ions remain essentially the same.

Membranes formulated with aminated-PVC $\left(\mathrm{NH}_{2}-\mathrm{PVC}\right.$; see Fig. 24$)$ offer particularly interesting possibilities for sensor development. This material has been prepared by refluxing diaminobutane (as well as other diamines) with PVC in methanol (Ma \& Meyerhoff, 1990). Films cast from this material display significant potentiometric $\mathrm{pH}$ response, even in the absence of an added $\mathrm{pH}$ ionophore (due to protonation of the amine sites). This is shown in Fig. 25. When another ionophore such as nonactin is added in excess mole ratio to the amine sites, the membrane gains selectivity for ammonium ions (as shown in Table 7). At the same time, the amine sites at the surface of the membrane can be used to immobilize bioreagents, including deaminating enzymes or specific antibodies. In one example, we immobilized monoclonal antibodies directed

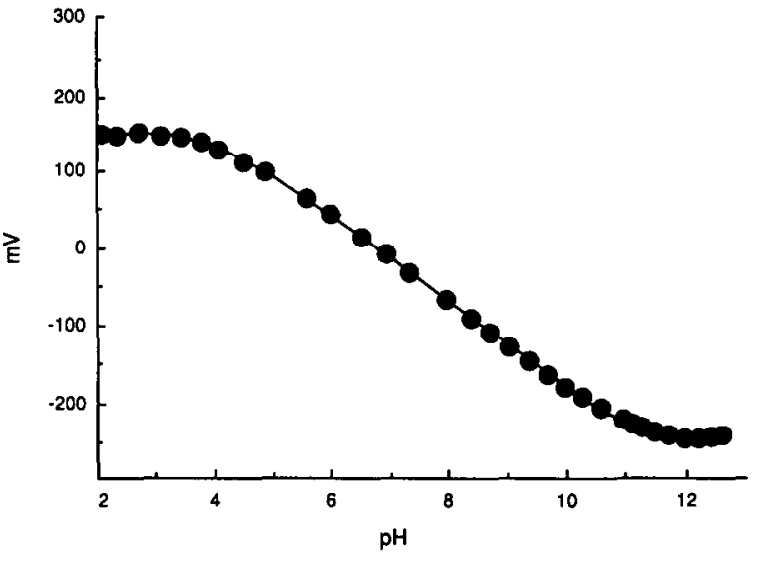

Fig. 25. Potentiometric $p H$ response membrane cast from 1,4-diaminobutane derivatized PVC (PVC-1,4-DAB).

toward urease (anti-urease), using a two-step glutaraldehyde method, to form a thin monolayer of antibody on the membrane electrode's surface (Ma et al., 1988). The electrode was then allowed to contact a solution containing urease so that the enzyme was immobilized via the immunorcaction with the monoclonal antibody. The resultant sensor displayed significant response to urea, indicating the enzyme-catalyzed formation of ammonium ions at the surface of the membrane.

While it was initially thought that the free carboxyl groups within membranes formulated with $\mathrm{COOH}-\mathrm{PVC}$ (carboxyl content $=1.87 \mathrm{wt} \%$ ) could be used for covalent attachment of enzymes and antibodies, it turns out that the carboxylic acid group remains fully protonated within the membrane even at very high bathing solution 
pHs (Ma et al., 1988). Thus typical activation procedures could not be used to directly couple proteins to the surface of such membranes. Anzai et al. (1987), however, have found that proteins do in fact stick quite tightly to $\mathrm{COOH}-\mathrm{PVC}$ membranes, although such adsorption can be readily reversed when the membranes are subjected to high ionic strength samples.

Ion-selective membranes prepared with poly(dimethyl)siloxane and PU/PVA polymer mixtures display very tight bonding to silicon materials, making them very attractive for the preparation of microfabricated devices. Efforts to use such membranes in solid-state devices are in progress (see Section 4.4 below and Cha et al., 1991).

\subsection{Asymmetric membrane-based enzyme electrodes}

Although aminated PVC materials can be used for direct covalent attachment of bioreagents to the surface of hydrophobic ion-selective polymer membranes, the number of amine sites available for direct covalent attachment is often quite low (Ma \& Meyerhoff, 1990), yielding sensors with poor bioreagent loading factors (i.e., a low density of enzyme or antibody per unit surface area). To overcome this limitation, we have investigated the possibility of preparing novel asymmetric ionselcctive polymer membranes in which a thin hydrophilic polymer membrane possessing a high density of functional groups is laminated or fused to an underlying more hydrophobic plasticized film containing the appropriate ion carrier. Potentiometric ion response of such asymmetric films thus occurs at the interface between the hydrophilic and hydrophobic membranes. Due to the high density of functional groups, the hydrophilic layer can serve as a thin support film for covalent immobilization of bioreagents, including enzymes.

Two such asymmetric polymer membrane systems have been devised for use in the preparation of potentiometric enzyme and immunoelectrodes. In one case, cellulose triacetate (CTA) is the base polymer membrane material (Cha \& Meyerhoff, $1989 a$ ), while in the other, a bilayer film of two types of polyurethane is employed. In the case of cellulose triacetate, Fig. 26 summarizes the steps required to prepare the asymmetric membranes, and the subsequent reactions that can be used to immobilize enzymes. The asymmetric membrane is formed by applying a thin layer (approximately $5 \mu \mathrm{m}$ thick) of cellulose triacetate without any membrane active components. One side of this membrane is then hydrolyzed by floating the membrane on a solution of strong base, thereby forming free hydroxyl groups. These groups can be either directly coupled with enzyme after activation in aqueous solution with carbonyl-diimidazole (CDI), or the CDI activation step can be followed by treatment with ethylenediamine to form an aminated membrane surface that can be subsequently activated with glutaraldehyde for enzyme immobilization. On the back side of the membrane, a second layer of cellulose acetate containing the appropriate neutral ion carrier and plasticizer is then cast. Ammonium, carbonate and $\mathrm{pH}$-sensitive membrane electrodes based on these asymmetric membranes (prepared with nonactin, trifluoroacetyl-p-butylbenzene and tridodecylamine, respectively; see Fig. 23 for structures) exhibit little or no change in response slope or selectivity compared to an unmodified cellulose triacetate membrane or conventional PVC-based electrodes.

As a model enzyme electrode system, we immobilized urease on the surface of both carbonate- and ammonium-selective electrodes prepared with asymmetric CTA-based membranes. Urease catalyses the following reaction (at $\mathrm{pHs} 7-9$ ):

$$
\begin{aligned}
& \left(\mathrm{NH}_{2}\right)_{2} \mathrm{CO}+3 \mathrm{H}_{2} \mathrm{O} \longrightarrow 2 \mathrm{NH}_{4}^{+}+\underset{\text { (reaction 3) }}{2 \mathrm{OH}^{-}} \\
& \quad+\mathrm{CO}_{2}
\end{aligned}
$$

Thus, each of the products can be detected directly by either of the asymmetric ion-selective membranes. In the case of the carbonate sensor, buffering the sample solution at $\mathrm{pH} 8.4$ allows a fixed fraction of the total carbon dioxide species formed at the surface of the electrode to be in the form of carbonate anions, detectable by the membrane doped with trifluoroacetyl-p-butylbenzene. The response slopes toward urea are, however, enhanced if the urease is immobilized on an asymmetric CTA membrane that responds potentiometrically to monovalent ammonium ions (rather than divalent carbonate). Figure 27 illustrates the dynamic potentiometric response of two such urea sensors to step changes in urea concentration. The two sensors differed with respect to the method used to immobilize the urease. In one case (curve A), a monolayer of enzyme was immobilized using the hydroxylated 

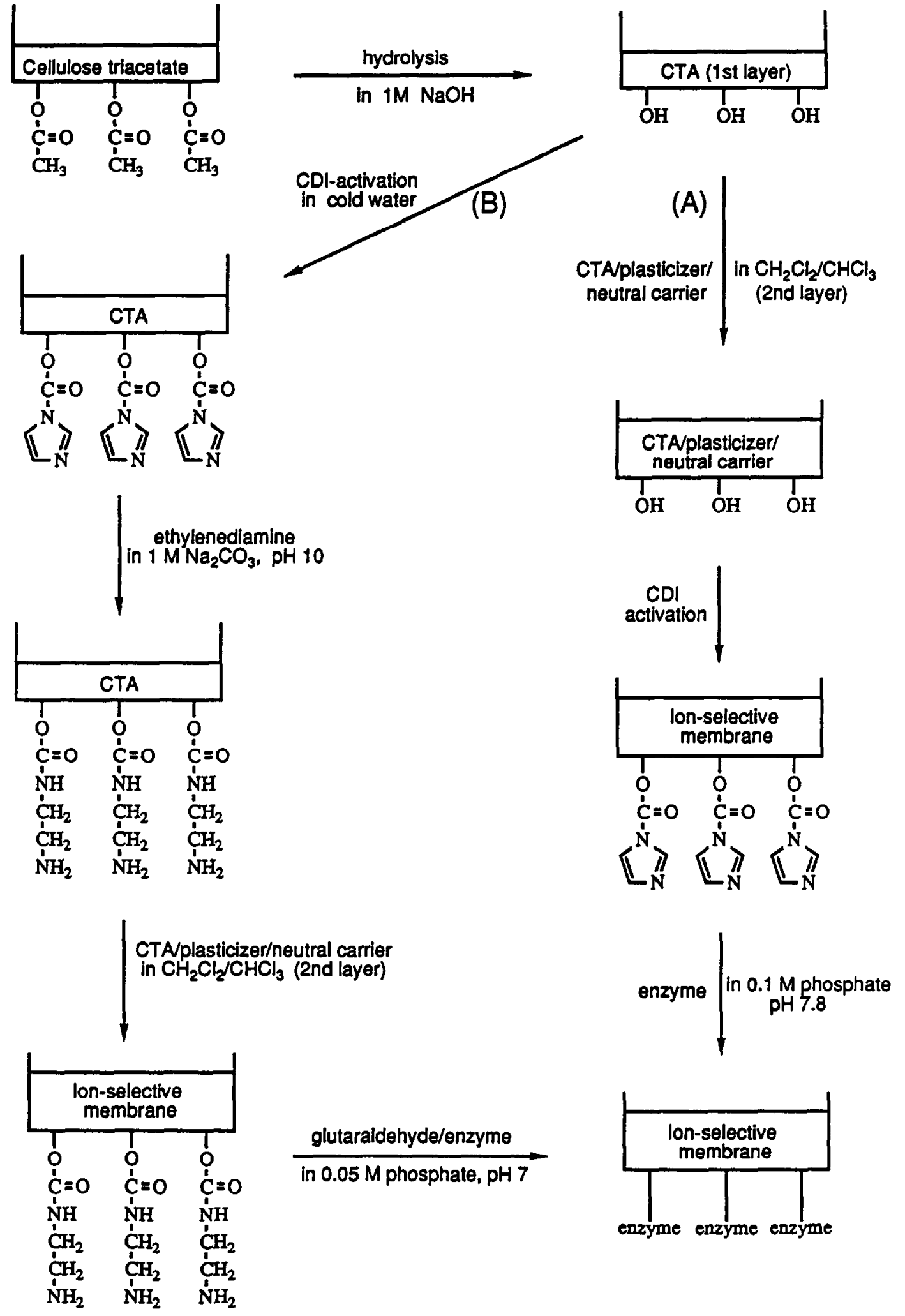

Fig. 26. General schemes used to prepare enzyme-immobilized asymmetric ion-selective cellulose triacetate membranes; (A) the direct CDI method for the hydroxylated membrane; (B) the glutaraldehyde method for membranes first reacted with CDI and then ethylenediamine. (From Cha \& Meyerhoff (1989a), with permission.) 


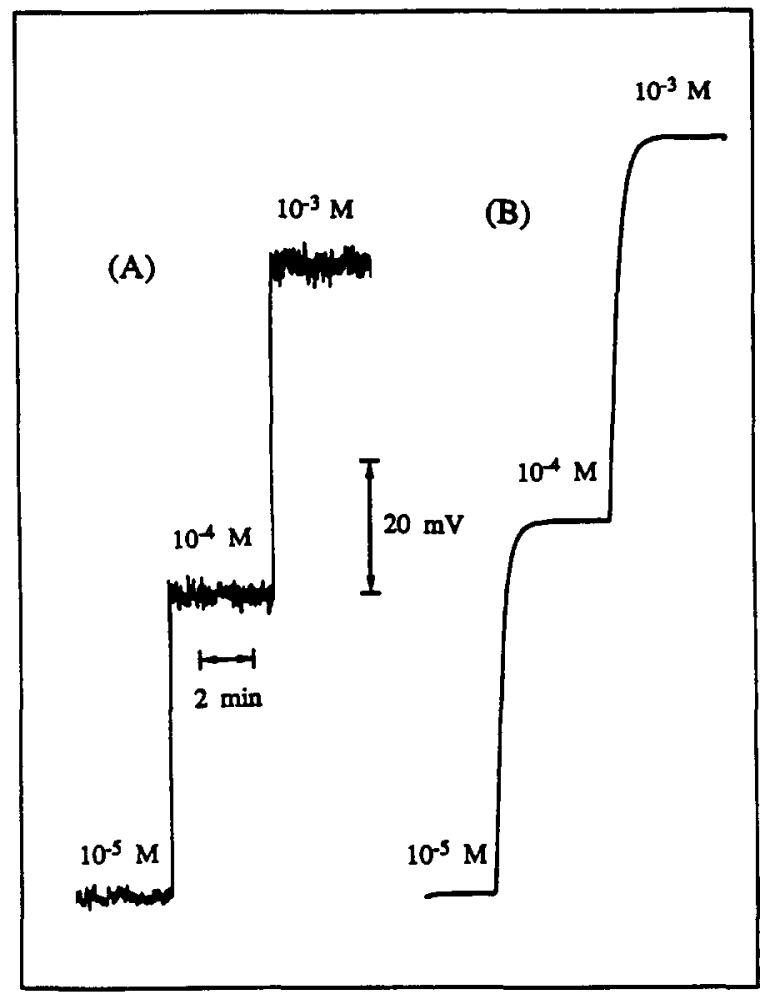

Fig. 27. Typical strip-chart recordings showing dynamic response of urea electrodes prepared by using asymmetric ammonium-selective cellulose triacetate membranes: (A) urease-hydroxylated membrane prepared by the direct CDI-activation method; (B) urease-aminated membrane prepared by the one-step glutaraldehyde method. (From Cha \& Meyerhoff (1989b), with permission.)

surface of the CTA through direct attachment of the enzyme via the CDI activation method (see Fig. 26), yielding a sensor with very rapid response time. Note that the noise on this tracing results from the effects of magnetic stirring, causing rapid fluctuations in the steady-state ammonium ion activities in the very thin monolayer of enzyme adjacent to the ion-selective CTA membrane. More stable steady-state potentials. albeit with somewhat slower response times, are obtained with a thicker crosslinked urease layer (curve B), prepared by first introducing amine groups onto the surface of the hydrolyzed CTA membrane.

The second asymmetric membrane system developed is based on polyurethane. As stated above, a mixture of Tecoflex polyurethane (PU) and the vinylchloride/vinylacetate/vinylalcohol terpolymer (PVA) provides an ion-selective membrane matrix (PU/PVA) that has excellent adhesion to silicon surfaces, as well as improved blood biocompatibility when compared to conventional PVC membranes (Cha et al., 1991). An asymmetric form of this membrane can be prepared by casting a thin second layer $(5-9 \mu \mathrm{m}$ thick) of a much more hydrophilic polyurethane material (adapted from Potter, 1985), containing $9 \mathrm{wt} \%$ of polylysine, onto the surface of a plasticized PU/PVA membrane containing an appropriate ionophore. A small volume of $0.02 \mathrm{M}$ $\mathrm{SiCl}_{4}$ (in $\mathrm{CH}_{2} \mathrm{Cl}_{2}$ ) is applied on the underlying polyurethane membrane surface immediately before casting the second hydrophilic layer to ensure good adhesion between the two polyurethane layers. When mounted in standard ionselective electrode bodies, the resulting asymmetric membranes function equivalently to normal PU/ PVA membranes in terms of ion response and selectivity. At the same time, the large amount of amine functional groups from the polylysine at the surface of the outer hydrophilic membrane can be further activated for direct enzyme immobilization. Again, ion extraction and charge separation are thought to occur at the interface of the non-plasticized hydrophilic membrane and the much more hydrophobic and well plasticized PU/PVA membrane containing the ion carrier (e.g., nonactin and tridodecylamine).

As initial examples, adenosine deaminase and urease have been immobilized on the ammonium- and proton-selective membranes by a one-step glutaraldehyde-activation method, yielding sensors that respond rapidly to adenosine and urea, respectively. Such sensors function for at least one month. with little loss in response slope (note: these sensors are prepared using a conventional ion-selective electrode arrangement: i.e. with an internal reference solution). Of course, when using the polymer $\mathrm{pH}$ electrode as the transducer for construction of the enzyme electrodes (in this case, for urea), the choice of sample buffer becomes critically important. As expected, lower ionic strength buffers yield the largest potentiometric response to urea. Thus, we typically employ $1 \mathrm{mM}$ Tris- $\mathrm{HCl} / 0 \cdot 1 \mathrm{M} \mathrm{NaCl}$ buffer, $\mathrm{pH} 7 \cdot 0$, for evaluation of enzyme electrode response.

\subsection{Enzyme-channeling immunosensor}

To extend the range of biological species that can be sensed with polymer membrane electrode detectors it is necessary to employ antibodies or 
other selective binding reagents in conjunction with various immunoassay schemes. Since the use of enzymes as labels in immunoassays is now commonplace, and many enzyme reactions can be monitored with appropriate ion-selective electrodes, adaptation of enzyme-immunoassays with potentiometric detection has received considerable attention in the literature over the past 10 years (Ngo, 1987; Monroe, 1984). For measurement of protein analytes, almost all enzyme-immunoassays (whether with or without electrochemical detection) a re carried out using a heterogeneous format (Gosling, 1990), involving multiple reagent additions and washing steps (i.e., to separate bound and free enzyme label). It would, therefore, be advantageous to devise an electrode-based enzyme-linked immunoassay technique for quantitation of proteins in which the sample and reagents can be added without the need for any discrete separation steps. Toward this goal, we recently described (Brown \& Meyerhoff, 1991) a novel assay system based on the use of an asymmetric ammonium-selective membrane electrode detector (such as that described in the preceding section) combined with the principles of enzyme channeling immunoassay (Litman et al., 1980).

The approach taken is based on the fact that ion-selective membrane electrodes sense the activity of ions that are at the surface of the sensor, not in the bulk solution. Thus, by using selective binding reactions to bring enzymes to the surface of the electrode, it is possible to discriminate product ions being formed at the surface (from added substrate) over the background enzymatic reactions occurring in the bulk, particularly if the bulk solution remains unstirred during the measurement period. The model system examined is illustrated in Fig. 28. An ammonium-selective cellulose triacetate membrane was used as a solid surface onto which both human IgG and adenosine deaminase (ADA) were immobilized (using method B in Fig. 26). The ADA serves as the second enzyme in a two-enzyme channeling sequence involving alkaline phosphatase (ALP)labeled protein-A (protein-A has a high affinity for IgG molecules). The two enzyme reactions are as follows:

$$
\begin{array}{ll}
\begin{array}{c}
\text { adenosine-5'-monophosphate } \\
\text { adenosine }+\mathrm{HPO}_{4}^{=}
\end{array} & \stackrel{\text { ALP }}{\longrightarrow} \\
\text { adenosine } \stackrel{\mathrm{ADA}}{\longrightarrow} \text { inosine }+\mathrm{NH}_{4}^{+} & \text {(reaction 4) }
\end{array}
$$

Using AMP as the substrate, the overall rate of ammonium ion formation by this two-step reaction is dependent on the proximity of the two enzymes. When the ALP is in the bulk solution (in the form of the ALP-protein-A conjugate), adenosine liberated from the ALP reaction must diffuse up to the electrode surface to react with

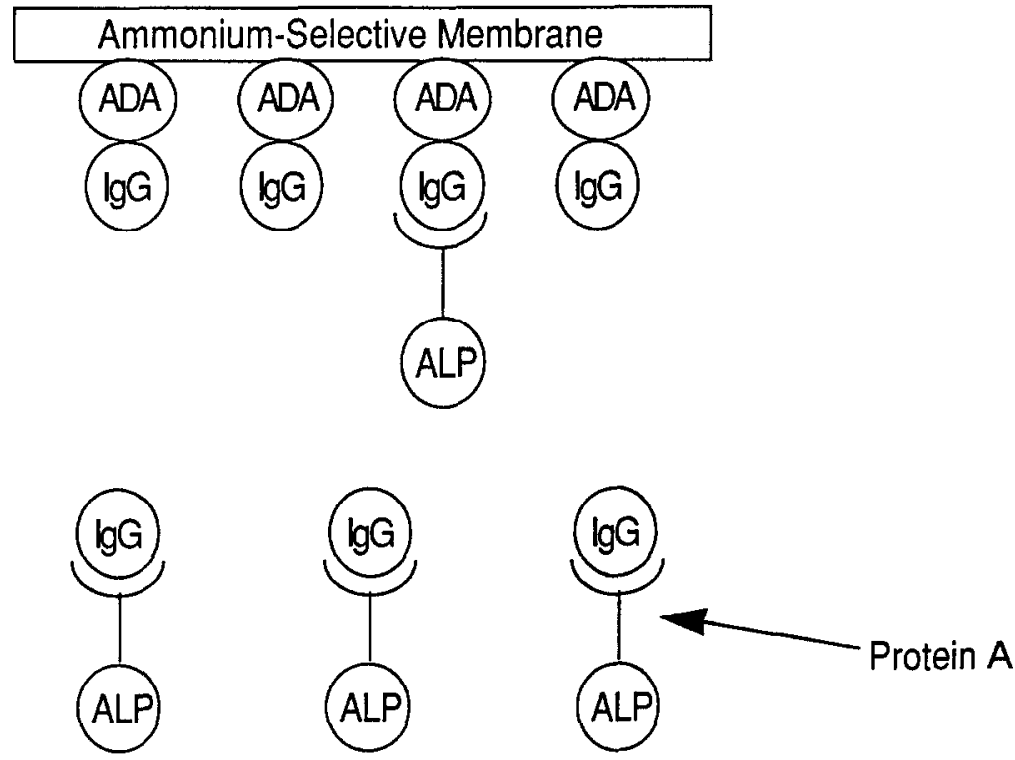

Fig. 28. Expanded view of the chemistry that occurs at the surface of an enzyme channeling immunosensor based on an asymmetric ammonium selective membrane detector, immobilized ADA and hIgG, and a soluble protein A-ALP conjugate. (From Brown \& Meyerhoff (199I). with permission.) 


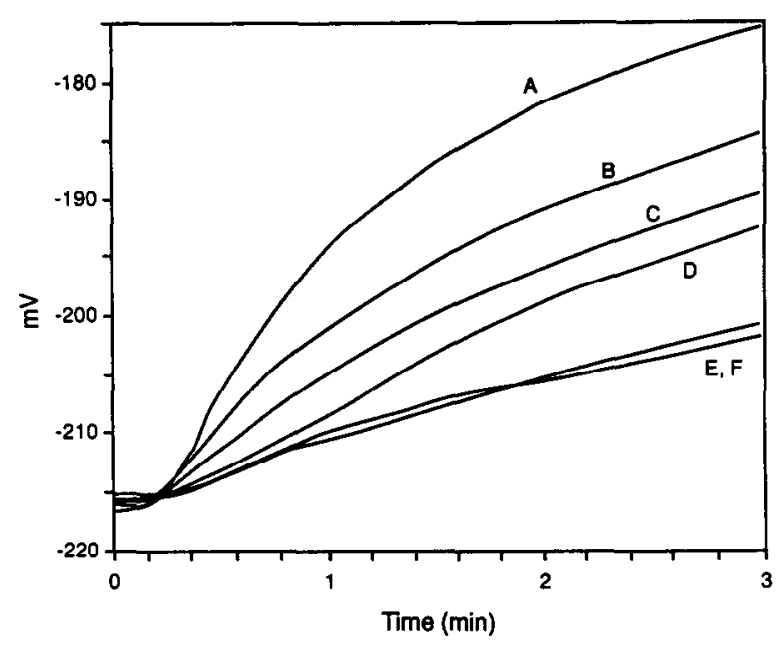

Fig. 29. Response of enzyme channeling immunosensor to varying levels of $I g G$ : (A) $0 \mu \mathrm{g} \mathrm{ml}^{-1} \mathrm{hlgG}$. (B) $5 \mu \mathrm{g} \mathrm{ml} l^{-1}$. (C) $10 \mu \mathrm{g} \mathrm{ml}^{-1}$. (D) $20 \mu \mathrm{g} \mathrm{ml}^{-1}$. (E) and (F) $50 \mu \mathrm{g} \mathrm{ml}^{-1}$ and blank response. (From Brown \& Meyerhoff (1991), with permission.)

ADA, thus producing a low rate of ammonium formation at the electrode surface (unchanneled reaction). When the ALP conjugate is brought up to the electrode surface via the selective reaction of protein-A with the co-immobilized IgG, the overall rate of the reaction is enhanced since there is essentially no diffusional barrier (channeled reaction). In the presence of analyte, in this case human IgG, the amount of ALPprotein-A conjugate bound to the surface is reduced due to competitive binding, and the rate of ammonium production after addition of AMP to the assay mixture is also greatly reduced.

In practice, a given amount of ALP-protein-A conjugate, the sample (containing IgG) and the electrode are incubated in an appropriate buffer (Tris- $\mathrm{HCl}, \mathrm{pH} \mathrm{8.5)} \mathrm{for} \mathrm{a} \mathrm{brief} \mathrm{period} \mathrm{of} \mathrm{time} \mathrm{(e.g.,}$ 10 min) with stirring. The AMP substrate is then added, mixed briefly, and then the stirring is stopped. The potential of the ammonium electrode is then monitored for several minutes. As shown in Fig. 29, the initial rate of potential change with time (i.e., $\mathrm{d}\left[\mathrm{NH}_{4}^{+}\right] / \mathrm{d} t$ ) is inversely related to the amount of analyte IgG protein present in the assay mixture. The detection limits of the assay can be varied by changing the amount of IgG immobilized on the surface of the asymmetric membrane, and/or the concentration of ALP conjugate used. No discrete separation step is required, although the solid phase of the electrode's surface essentially creates a pseudo- separation phase in terms of the physical location of the ALP-protein-A conjugate. Note that, in the presence of excess analyte protein, there is still a significant rate observed for the two-step reaction that is much greater than predicted by our simple model (Brown \& Meyerhoff, 1991). This appears to be primarily due to the contamination of some ALP in the ADA preparation immobilized on the surface of the asymmetric membrane (Brown \& Meyerhoff, 1991). The sensor can be reused for about eight separate measurements by dissociating the protein-A-IgG binding reaction using $0 \cdot 1 \mathrm{M}$ guanidine- $\mathrm{HCl}$ buffer, $\mathrm{pH} 3 \cdot 0$.

The enzyme channeling electrode system has been tested for analytical utility by determining human IgG levels in human serum samples. Figure 30 shows the correlation obtained when the electrode-based enzyme channeling method was compared to values measured by a standard nephelometric technique for 9 samples obtained from the University of Michigan Hospital. Good agreement was observed between the two methods $(r=0.985)$.

It is important to note that this IgG assay system is only meant to serve as an example of what might be possible using membrane electrodes in pseudo-homogeneous enzyme-linked binding and immunoassays. Clearly, the measurement of IgG in serum does not represent a significant analytical challenge. Given its high concentration, a number of rapid turbidimetric/nephelometric methods are suitable for this particular protein analyte. However, if the principles of this assay scheme could be adopted to other protein analytes, particularly through the use of selective ALP-antibody conjugates, some very attractive non-separation immunoassay methods could emerge. Especially exciting would be the marriage of this approach to the conventional noncompetitive sandwich immunoassay scheme commonly employed to detect low concentrations of physiologically important proteins (Monroe. 1984; Gosling, 1990). In such a method, ALP would need to be coupled to a monoclonal antibody directed towards one determinate site of the analyte protein, and a second monoclonal antibody directed toward another site of the protein would need to be immobilized along with ADA at the surface of the electrode. The attractive feature of this sandwich arrangement is that increasing analyte protein concentrations would result in an increase in channeled rate for the overall two-step enzymatic reaction (non- 


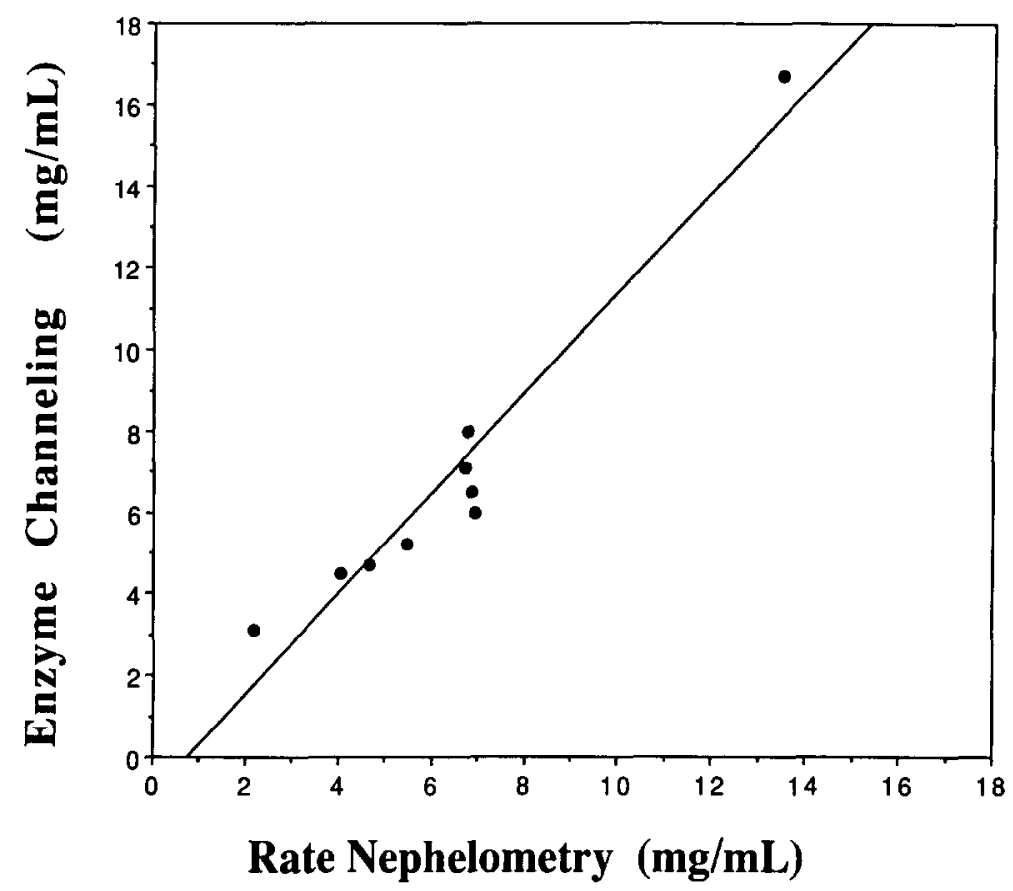

Fig. 30. Correlation data for determination of $\operatorname{Ig} G$ in human serum using enzyme channeling immunosensor and rate nephelometry method $\left(\mathrm{y}=1.23 \mathrm{x}-0.941, \mathrm{r}^{2}=0.970\right)$. (From Brown \& Meyerhoff (1991), with permission.)

competitive assay). This should enhance the detection limits of the electrode-based method.

\subsection{Solid-state biosensors}

In recent years, there has been considerable interest in the development of solid-state potentiometric ion sensors and biosensors, in which polymer membranes are cast directly on the surface of the miniaturized solid-state sensing sites with no internal reference electrolyte solutions (McBride et al., 1978; Scheller et al., 1991; Van Der Wal et al., 1990). These devices are usually made on silicon wafer with or without integrated electronic circuits underneath. Such devices can offer the advantages of miniaturization (for future in vivo measurements), the capability of including multiple sensors or sensor arrays on a single chip, integration of signal processing circuitry, and mass fabrication for cost reduction. Miniaturized sensor arrays containing ion sensors and biosensors can be used as either single-use disposable devices or as multisensor electrochemical detectors within modern flow-injection analysis instrumentation.

The major problem encountered previously when attempting to fabricate analytically useful solid-state ion sensors or biosensors is poor polymer membrane (e.g., PVC-based) adhesion to the solid surface, yielding rapid sensor failure (i.e., short circuiting the ion-selective membrane). Further immobilization of enzymes or other bioreagents has been difficult owing to the lack of functional groups on the polymers used to fabricate such devices. Ion-selective membranes prepared with several of the new polymer matrices described above (Section 4.1) have already demonstrated significantly enhanced adhesion properties to silicon materials, as measured quantitatively with a well controlled mechanical pulling force tester (Cha et al., 1991). Particularly attractive are ion-selective membranes prepared with a mixture of PU and PVA polymers, since such PU/PVA films can be further treated with a thin layer of hydrophilic polyurethane containing polylysine to yield asymmetric coatings for enzyme immobilization.

Our initial potentiometric solid-state biosensor design is illustrated in Fig. 31. Aluminum conductor leads are patterned on silicon wafers, and insulated (except at the sensing site) with silicon nitride. A layer of silver epoxy is then coated over the aluminum. A thin $(100-300 \mu \mathrm{m})$ layer of a plasticizer/PU/PVA polymer cocktail containing an appropriate ionophore (usually nonactin or tridodecylamine for fabrication of 


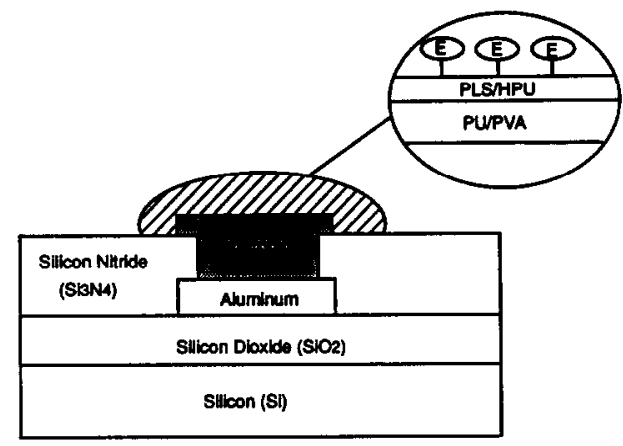

Fig. 31. Side view of solid-state sensor coated with asymmetric polyurethane-based ion-selective membrane.

biosensors) can then be cast onto the silver epoxy layer, yielding tight adhesion to both the epoxy and the surrounding silicon nitride coating of the wafer. At this point, the sensor can be used as a solid-state ion-selective electrode, with response properties nearly equivalent to those of standard conventional PVC membrane electrodes prepared with internal reference solutions. The addition of the final very thin hydrophilic polyurethane/ polylysine layer allows for direct attachment of enzymes and antibodies to the surface. Each of the films, starting with the silver epoxy layer, can be screen-printed for mass fabrication purposes. In addition, the size and number of sensing regions per unit area of the silicon wafer can be varied. While our initial work has been conducted using single sensor devices that are rather large $(1 \mathrm{~cm} \times 1 \mathrm{~cm})$ and connected to external operational amplifier circuits for measuring the potentiometric signals, we are now developing smaller chips containing multiple polymer membrane sensors, with on-chip signal processing (i.e., an operational amplifier under each sensing site).

When urease is immobilized on the surface of an asymmetric ammonium-selective solid-state device (using a one-step glutaraldehyde method), the resulting solid-state biosensor responds rapidly ( $\leqslant 30 \mathrm{~s}$ ) and selectively to urea (Fig. 32 ). The typical calibration curve of this solid-state urea sensor, based on the ammonium-selective asymmetric membrane, is shown in Fig. 33. The slope of $55.6 \mathrm{mV}$ per decade and the wide dynamic range of response $\left(10^{-5}\right.$ to $10^{-2} \mathrm{M}$ urea) suggests that high enzyme loading can be achieved on the surface of asymmetric membranes. In the case of an adenosine sensor prepared in the same manner (using adenosine deaminase as the

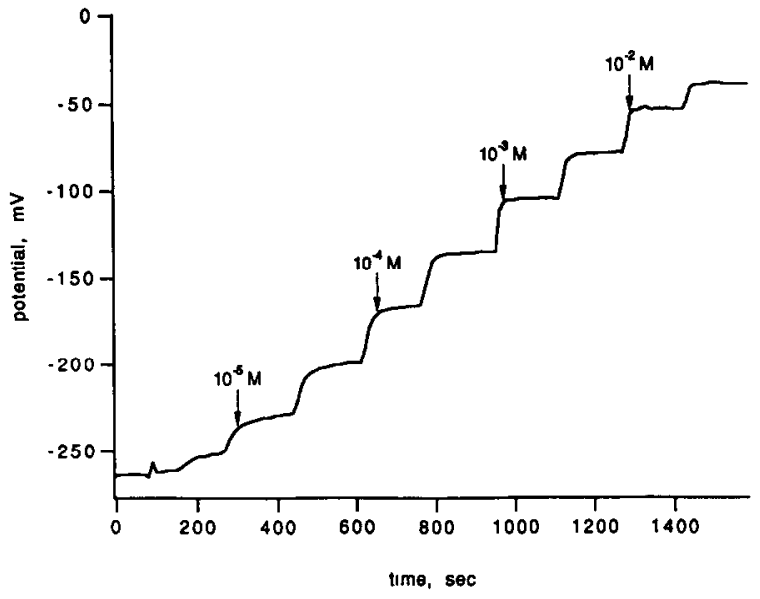

Fig. 32. Dynamic response of solid-state urea sensor prepared by immobilizing urease on ammonium-selective asymmetric polyurethane membrane.

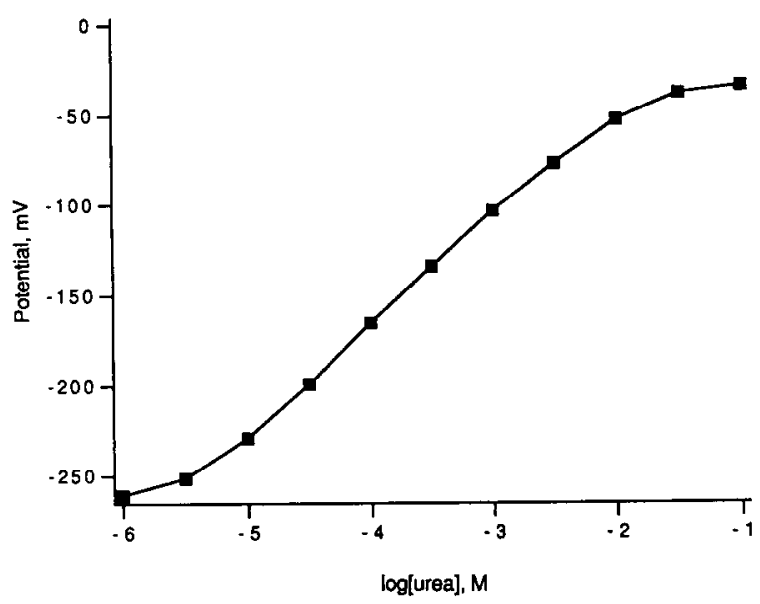

Fig. 33. Typical calibration curve for solid-state urea sensor based on the asymmetric polyurethane membrane.

immobilized enzyme), the slope and detection limits toward adenosine remained essentially constant during one month of continuous testing.

At this point, we are investigating new methods to site direct, through photochemical reactions, the immobilization of enzymes (and antibodies) on the surfaces of such solid-state polymer membrane base sensors, to improve the mass fabrication prospects for such devices. Ultimately we believe that combination ion sensor/biosensor arrays based on this technology can be used as maintenance-free disposable detectors in a wide variety of clinical chemistry instrumentation or single use immunoassays, such as the enzyme channeling method described above. 


\section{SUMMARY AND FUTURE DIRECTIONS}

It is clear from the research activities described in this review that polymer membrane electrode technology offers a number of interesting and potentially attractive options for monitoring ions, gases and biomolecules in complex biological samples. The key to success in this area is to achieve a high degree of ion selectivity at the polymer membrane/sample interface via appropriate membrane chemistries. While this is now possible in the case of simple cations, the development of analogous electrochemical sensors suitable for the detection of anions, gases, and more complex biological molecules, including metabolites, proteins and drugs, is still in its infancy.

As described in Section 2, various metalligand complexes, including metalloporphyrins and polyporphyrins, are being examined as anion-selective complexing agents, and some success in devising analytically useful devices has already been accomplished with such systems. However, additional anion complexing agents are sorely needed both for the direct detection of given anions and for the development of novel biosensors. For example, if a polymer membrane could be developed that exhibited high selectivity for inorganic phosphate $\left(\mathrm{HPO}_{4}^{-}\right)$, such a sensor could be useful for in situ detection of phosphate in biological samples as well as being a base transducer to prepare a multitude of new enzyme electrodes using a variety of dephosphorylating enzymes (e.g., for adenosine triphosphate (ATP) etc.). Macrocyclic organometallics, with multiple electron-deficient metal centers spatially arranged to yield enhanced interaction with given polyatomic anions (i.e., the oxygen atoms of phosphate), may prove useful for this purpose. Macrocyclic quaternary ammonium species may also be attractive candidates as membrane-active species in new anion electrodes.

A variety of novel potentiometric gas sensors were described in Section 3. While such sensors have application in many areas, including environmental air and water analysis, efforts on devising polymer-membrane electrodes for in vivo monitoring have become a major focus of our current efforts. In this regard, the new oxygensensing chemistry involving membranes doped with $\mathrm{Co}$ (II) complexes could ultimately be used to devise an all potentiometric $\mathrm{pH} / \mathrm{PCO}_{2} / \mathrm{PO}_{2}-$ sensing catheter implementing the simple dual lumen geometry depicted in Fig. 20. In principle, potentiometric equilibrium-type oxygen sensors could be more reliable than existing amperometric devices, particularly for long-term in vivo measurements, since the kinetic response of the latter varies substantially with time, depending on the permeability of the outer gas diffusion membrane toward $\mathrm{O}_{2}$.

Expanding the analytical capabilities of polymer membrane electrodes to include the detection of high molecular weight species such as drugs, proteins, hormones etc. represents an even greater challenge. While some exciting results have been achieved recently in the case of macromolecular heparin (see Section 2.2), this is a rather unique case (i.e., a polyanion species) and the design of direct ion sensors (based on polymer membrane extraction) for other mixed charged macromolecules will be more difficult. Thus, to extend the range of measurable species it will be necessary to rely on the use of indirect sensing arrangements, involving the combination of enzymes and immunological reactions. The enzyme-channeling scheme described in Section 4.3 represents only one possible approach. While other arrangements employing immobilized bioreagents can be envisioned, including ones requiring washing steps, in most cases (with the exception of true enzyme electrodes) it is likely that the resulting biosensing systems will be single-use-type probes, or ones that can be used only after some regeneration step (addition of chaotropic reagent, etc.). It is for this reason that preparation of such sensors using mass fabrication semiconductor technology seems an attractive and appropriate direction for the future. Our work with new ion-selective polymer membrane materials and asymmetric membrane systems that adhere tightly to silicon-based substrates may prove quite valuable in connection with this objective.

Finally, while this entire review has dealt with the use of polymer membranes in the design of potentiometric sensors, many of the chemistries described herein should also be applicable to the development of novel optical ion-, gas- and bioselective sensors. Indeed, Wolfbeis (1991) has recently reviewed the current state-of-the-art in optical chemical sensors, and many of the newer ion-sensing schemes are in fact based on the same membrane carriers used for years to fabricate ion-selective electrodes. For example, an ammonium-responsive optical sensor can be 
prepared by incorporating nonactin (compound $\underline{7}$ in Fig. 23) along with an appropriate lipophilic acid-base indicator within a very thin plasticized PVC membrane (Ozawa et al., 1991). When ammonium ions are extracted into the membrane, a proton is expelled, causing a change in the absorbance of the indicator within the organic membrane phase. Thus, our asymmetric membrane systems (see Section 4.2) could, in principle, also be adopted for designing novel fiber-optic-type enzyme-based sensors. Similarly, our efforts to find new polymer matrices that adhere tightly to silicon substrates could ultimately prove useful in the development of novel solid-state ion-, gas- and bio-selective optical sensors, in which the membranes are coated over arrays of photodiode detectors incorporated within the silicon chips. The possibilities in this area are enormous provided that the chemistry really works. It is for these reasons that, within our existing electrochemical work, we choose to emphasize the chemistry side of the sensor system since, without selective and stable chemistry, no sensor can be implemented for real-world measurements in complex biological samples.

\section{REFERENCES}

Ammann, D., Pretsch, E., Lindner, E., Bezegh. A. Pungor, E. \& Simon, W. (1985). Lipophilic salts as membrane additives and their influence on the properties of macro- and micro-electrodes based on neutral carriers. Anal. Chim. Acta. 171, 119.

Anzai, J., Shimada, M., Osa, T. \& Chen, C. (1987). Enzyme sensors based on coated-wire electrode use of carboxyl-substituted poly(vinyl chloride) as a support for immobilizing penicillinase. Bull. Chem. Soc. Jpn., 60, 4133.

Arnold, M. A. \& Meyerhoff, M. E. (1984). Ion-selective electrodes. Anal. Chem., 56, $20 \mathrm{R}$.

Arnold, M. A. \& Solsky, R. L. (1986). Ion-selective electrodes. Anal. Chem., 58, 84R.

Bailey, P. L. \& Riley, M. (1975). Performance characteristics of gas-sensing membrane probes. Analyst. $100,145$.

Bettelheim, A., White, B., Raybuck, S. \& Murray, R. W. (1987). Electrochemical polymerization of amino-, pyrrole-, and hydroxy-substituted tetraphenylporphyrins. Inorg. Chem., 26, 1009.

Bowler, R. G. (1944). The determination of thiocyanate in blood serum. Biochem. J., 38, 385.

Brown, D. V. \& Meyerhoff, M. E. (1991). Potentiometric enzyme channeling immunosensor for proteins. Biosensors \& Bioelectronics, 6, 615.

Brown, D. V., Chaniotakis, N. A., Lee, I. H., Ma, S. C., Park, S. B., Meyerhoff, M. E., Nick, R. J. \& Groves, J. T. (1989). Mn(III)-porphyrin-based thiocyanateselective membrane electrodes: characterization and application in flow injection determination of thiocyanate in saliva. Electroanalysis, 1, 477.

Byrne, T. P. (1988). Ion-selective electrodes in direct potentiometric clinical analyzers. Selective Elect. Rev., 10, 107.

Carr, P. W. \& Bowers. L. D. (1980). Immobilized Enzymes in Analytical and Clinical Chemistry. Wiley-Interscience, New York, Chap. 5.

Cha, G. S. \& Meyerhoff, M. E. (1989a). Potentiometric ion- and bio-selective electrodes based on asymmetric cellulose acetate membranes. Talanta, 36, 271.

Cha, G. S. \& Meyerhoff, M. E. (1989b). Enzyme electrode-based differential potentiometric cell with enhanced substrate sensitivity. Electroanalysis. $1,205$.

Cha, G. S., Liu, D., Meyerhoff, M. E., Cantor, H. C., Midgley, A. R., Goldberg, H. D. \& Brown, R. B (1991). Electrochemical performance, biocompatibility, and adhesion of new polymer matrices for solid-state ion sensors. Anal. Chem., 63, 1666.

Chang, Q., Park, S. B., Kliza, D., Cha, G. S., Yim, H. \& Mcycrhoff, M. E. (1990). Recent advances in the design of anion-selective membrane electrodes. Amer. Biotech. Lab., 8, 10.

Chaniotakis, N. A., Chasser, A. M., Meyerhoff, M. E. \& Groves, J. T. (1988). Influence of porphyrin structure on anion selectivities of manganese(III) porphyrin-based membrane electrodes. Anal. Chem., 60, 188.

Chaniotakis, N. A., Park, S. B. \& Meyerhoff, M. E. (1989). Salicylate-selective membrane electrode based on tin(IV) tetraphenylporphyrin. Anal. Chem., 61, 566.

Clark, L. C. Jr (1956). Monitoring and control of blood and tissue oxygen tensions. Trans. Amer. Soc. Ant. Int. Organs, 2, 41.

Collison, M. E. \& Meyerhoff, M. E. (1989). Catheter-type Electrochemical Sensors, U.S. Patent 4834101.

Collison, M. E., Aebli, G. V.. Petty. J. \& Meyerhoff, M. E. (1989). Potentiometric combination ion/carbon dioxide sensors for in vitro and in vivo blood measurements. Anal. Chem., 61, 2365.

Craggs, A., Moody, G. J. \& Thomas, J. D. R. (1974). PVC matrix membrane ion-selective electrodes. J. Chem. Educ., 51, 541.

D’Orazio, P. \& Rechnitz, G. A. (1977). Protein response of silver sulfide crystal membrane electrodes. Anal. Chem., 49, 41.

Danishefsky, I., Rosenfeld, L., Kuhn, L., Lahiri, B. \& Whyzmuzis, C. (1989). Heparin and related polysaccharides, structure and activities. In: $A n n$. 
New York Acad. Sci. 556, ed. Ofosu. F. A. et al., The New York Academy of Sciences. New York, p. 29.

Daunert, S., Wallace, S., Florido, A. \& Bachas, L. (1991). Anion-selective electrodes based on electropolymerized porphyrin films. Anal. Chem., 63, 1676.

Dong, S.. Sun, Z. \& Lu, Z. (1988a). A new kind of chemical sensor based on conducting polymer film. J. Chem. Soc. Chem. Commun., 105, 993.

Dong, S.. Sun, Z. \& Lu, Z. (1988b). Chloride chemical sensor based on an organic conducting polypyrrole polymer. Analyst, 113, 152.

Fraticelli, Y. M. \& Meyerhoff, M. E. (1981). Selectivity characteristics of a mmonia-gas sensors based on a polymer membrane electrode. Anal. Chem., 53, 1857.

Glacken. M. W., Fleischaker, R. J. \& Sinskey, A. J. (1986). Reduction of waste product excretion via nutrient control: possible strategies for maximizing product and cell yields on serum in cultures of mammalian cells. Biotechnol. Bioeng., 28, 1376.

Glazier, S. A. \& Arnold, M. A. (1989). Progress in phosphate-selective electrode development. Anal. Lett., 22, 1075

Godal, H. C. (1960). A comparison of two heparinneutralizing agents: protamine and polybrene. Scandinav. J. Clin. Lab. Invest., 12, 446.

Gosling, J. P. (1990). A decade of development in immunoassay methodology. Clin. Chem., 36, 1408.

Greenberg, J. A. \& Meyerhoff, M. E. (1982). Response properties, applications and limitations of carbonate selective polymer membrane electrodes. Anal. Chim. Acta, 141, 57.

Grode, G. A., Falb, R. D. \& Crowley, J. P. (1972). Biocompatible materials for use in the vascular system. J. Biomed. Mater. Res. Symp, 3, 77.

Guilbault, G. G. (1976). Handbook of Enzymatic Methods of Analysis. Marcel Dekker, New York. Chap. 5.

Guilbault, G. G. (1984). Analytical Uses of Immobilized Enzymes. Marcel Dekker, New York, pp. 112.

Heineman, W., Wieck, H. \& Yacynych, A. (1980). Polymer film modified electrode as a potentiometric sensor. Anal. Chem., 52, 345.

Herman, H. B. \& Rechnitz, G. A. (1974). Carbonate ionselective membrane electrode. Science, 49, 41.

Hodinár, A. \& Jyo, A. (1988). Thiocyanate solvent polymeric membrane ion-selective electrode based on cobalt(III) $\alpha, \beta, \gamma, \delta$-tetraphenylporphyrin anion carrier. Chem. Lett., 993.

Hofmeister, F. (1888). Zur Lehre von der Wirkung der Salze. Arch. Exp. Pathol. Pharmaakol., 24, 247.

Huang, W., Humphrey, B. \& MacDiarmid, A. G. (1986). Polyaniline, a novel conducting polymer. J. Chem. Soc. Faraday Trans., 1, 82, 2385.

Huser, M., Morf, W. E., Fluri, K., Seiler, K., Schulthess, P. \& Simon, W. (1990). Transport properties of anion-selective membranes based on cobyrinates and metalloporphyrin complexes as ionophores. Helv. Chim. Acta, 73, 1481.

Jaques, L. B. (1979). Heparins: anionic polyelectrolyte drugs. Pharmacol. Rev., 31, 99.

Jin, L., Shi, Z., Ye, J., Qian, J. \& Fang, Y. (1991). Use of a poly $(4,4$ '-diamino-biphenyl) chemically modified electrode. Anal Chim. Acta, 244, 165.

Jones, R. D., Summerville, D. A. \& Basolo, F. (1979). Synthetic oxygen carriers related to biological systems. Chem. Rev., 79, 139.

Karagozler, A., Ataman, O., Galal, A., Xue, Z., Zimmer, H. \& Mark, H. B. (1991). Potentiometric iodide ion sensor based on a conducting poly(3-methylthiophene) polymer film electrode. Anal. Chim. Acta, 248, 163.

Karube, I. \& Suzuki, S. (1984). Amperometric and potentiometric determinations with immobilized enzymes and microorganisms. Ion-Selective Electrode Rev, 6, 15.

Kliza, D. M. \& Meyerhoff, M. E. (1992). Potentiometric anion response of poly(tetrakis( $p$-aminophenyl)porphyrin) film modified electrodes. Electroanalysis, 4, 841 .

I ewenstam, A., Maj-Zurawska, M. \& Hulanicki, A. (1991). Application of ion-selective electrodes in clinical analysis, Electroanalysis, 3, 727.

Litman, D. J., Hanlon, T. M. \& Ullman, E. F. (1980). Enzyme channeling immunoassay: a new homogenous enzyme immunoassay technique. Anal. Biochem., 106, 223.

Lu, Z., Sun, Z. \& Dong, S. (1989). Study of $\mathrm{ClO}_{4}^{-}$-selective electrode based on a conducting polymer polypyrrole. Electroanalysis, 1, 271.

Ma, S. C. \& Meyerhoff, M. E. (1990). Potentiometric pH response of membranes prepared with various aminated-poly(vinyl chloride) products. Mikrochimica Acta, I, 197.

Ma, S. C., Chaniotakis, N. A. \& Meyerhoff, M. E. (1988). Response properties of ion-selective polymeric membrane electrodes prepared with aminated and carboxylated poly(vinyl chloride). Anal. Chem., 60, 2293.

Ma, S. C., Meyerhoff, M. E. \& Yang, V. C. (1992). Heparin-responsive electrochemical sensor: a preliminary study. Anal. Chem., 64, 694.

Martin, G. B. \& Meyerhoff, M. E. (1986). Membranedialyzer injection loop for enhancing the selectivity of anion-responsive liquid-membrane electrodes in flow systems. Anal. Chim. Acta, 186, 71.

McBride, P. T., Janata, J., Comte, P. A. Moss, S. D. \& Johnson, C. C. (1978). Ion-selective field effect transistors with polymeric membranes. Anal. Chim. Acta, 101, 239.

McLendon, G. \& Martell, A. E. (1976). Inorganic oxygen carriers as models for biological systems. Coord. Chem. Rev., 19, 1.

Meier, P. C., Morf, W. E., Laubli, M. \& Simon, W. (1984). Evaluation of the optimum composition of 
neutral-carrier membrane electrodes with incorporated cation-exchanger sites. Anal. Chim. Acta, 156, 1.

Meyerhoff, M. E. (1980). Polymer membrane electrode based potentiometric ammonia gas sensor. Anal. Chem., 52, 1532.

Meyerhoff, M. E. (1990). New in vitro analytical approaches for clinical chemistry measurements in critical care. Clin. Chem., 36, 1567.

Meyerhoff, M. E., Fraticelli, Y. M., Greenberg, J. A. Rosen, J., Parks, S. J. \& Opdycke, W. N. (1982). Polymer-membrane electrode-based potentiometric sensing of ammonia and carbon dioxide in physiological fluids. Clin. Chem., 28, 1973.

Meyerhoff, M. E., Fraticelli, Y. M., Opdycke, W. N. Bachas, L. G. \& Gordus, A. D. (1983). Theoretical predictions on the response properties of potentiometric gas sensors based on internal polymer membrane electrodes. Anal. Chim. Acta, 154, 17.

Meyerhoff, M. E., Pretsch, E., Welti, D. H. \& Simon, W. (1987). Role of trifluoroacetophenone solvents and quaternary ammonium salts in carbonate-selective liquid membrane electrodes. Anal. Chem., 59, 144.

Meyerhoff, M. E., Pranitis, D. M., Yim, H. S., Chaniotakis, N. A.\& Park, S. B. (1989). New anionand gas-selective potentiometric sensors. In: Chemical Sensors and Microinstrumentation, ed. Murray, R. W. et al. American Chemical Society, Washington, DC, pp. 26.

Misiano. D. R. \& Lowenstein. E. (1988). Performance characteristics of the Gem-Stat monitor. Proc. Int. Fed. Clin. Chem., Stresa, Italy, 10, 239.

Monroe, D. (1984). Enzyme immunoassay. Anal. Chem., 56, 920A.

Morf, W. E. (1981). The Principles of Ion-Selective Electrodes and of Membrane Transport. Elsevier, Amsterdam.

Ngo, T. T. (ed.) (1987). Electrochemical Sensors in Immunological Analysis. Plenum Press, New York.

Niederhoffer, E. C., Timmons, J. H. \& Martell, A. E. (1984). Thermodynamics of oxygen binding in natural and synthetic dioxygen complexes. Chem. Rev., 84, 137.

Oesch, U., Ammann, D. \& Simon, W. (1986). Ionselective membrane electrodes for clinical use. Clin. Chem., 32, 1448.

Opdycke, W. N. \& Meyerhoff, M. E. (1986). Development and analytical performance of tubular polymer membrane electrode based carbon dioxide catheters. Anal. Chem., 54, 950.

Opdycke, W. N., Parks, S. J. \& Meyerhoff, M. E. (1983). Polymer-membrane $\mathrm{pH}$ electrodes as intemal elements for potentiometric gas-sensing systems. Anal. Chim. Acta. 155, 11.

O'Reilly, R. A. (1985). Anticoagulent, antithrombic and thrombolytic drugs. In: Goodman and Gilman, the Pharmacological Basis of Therapeutics, ed. Gilman,
A. G. et al. Macmillan Publishing Co, New York, 7th edn, Chap 58.

Ozawa, S., Hauser, P. C., Seiler, K., Tan, S. S. S., Morf, W. E. \& Simon, W. (1991). Ammonia-gas-selective optical sensors based on neutral ionophores. Anal. Chem., 63, 640.

Park. S. B., Matuszewski. W., Meyerhoff, M. E., Liu, Y. H. \& Kadish, K. M. (1991). Potentiometric anion selectivities of polymer membranes doped with indium(III)-porphyrins. Electroanalysis, 3, 909.

Potter, W. D. (1985). Electrochemical Sensor Employing a Gas-Permeable Hydrophilic Polyurethane Membrane. US Patent 4534355.

Pranitis, D. M. \& Meyerhoff, M. E. (1989). Sulfitesensitive solvent/polymeric-membrane electrode based on bis(diethyl-dithiocarbamato)mercury(II). Anal. Chim. Acta, 217, 123.

Pressprich, K., Maybury, S., Thomas, R., Linton, R., Irene, E. \& Murray, R. W. (1989). Molecular sieving by electropolymerized porphyrin films only a few monolayers thick. J. Phys. Chem., 93, 5568.

Rechnitz, G. A. (1981). Bioselective membrane electrode probes. Science, 214, 287.

Riley, J. B. (1987). In vitro measu rement of the accuracy of a new patientside blood gas monitor. J. Extracorpor. Technol., 19, 322.

Ross, J. W., Riseman, J. H. \& Krueger, J. A. (1973). Potentiometric gas sensing electrodes. Pure Appl. Chem., 36, 473.

Scheller, F. W., Hintsch, R., Pfeiffer, D., Schubert, F., Riedel. K. \& Kindervater. R. (1991). Biosensors: fundamentals, applications and trends. Sens. Actuators B, 4, 197.

Schulthess, P., Ammann, D., Simon, W., Caderas, C., Stepánek, R. \& Kräutler, B. (1984). A lipophilic derivative of vitamin $B_{12}$ as a selective carrier for anions. Helv. Chim. Acta, 67, 1026.

Schulthess, P., Ammann, D., Kräutler, B., Caderas, C., Stepánek, R. \& Simon, W. (1985). Nitrite-selective liquid membrane electrode. Anal. Chem., 57, 1397.

Severinghaus, J. W. \& Bradley, A. F. (1958). Electrodes for blood $P_{\mathrm{O}_{2}}$ and $P_{\mathrm{CO}_{2}}$ determinations. J. Appl. Physiol.. 13, 515.

Sharp, M. (1975). An examination of some active organometallic substances for ion-selective electrodes. Anal. Chim. Acta, 76, 165.

Solsky, R. L. (1988). Ion-selective electrodes. Anal. Chem., 60, 106R.

Stefanac, Z. \& Simon, W. (1966). In-vitro Verhalten von Makrotetroliden in Membranen als Grundlage für hochselektive Kationen spezifische Elektrodensysteme. Chimia, 20, 436.

Stewart, M.S. \& Watson, I. D. (1987). Analytical reviews in clinical chemistry: methods for the estimation of salicylate and paracetamol in serum, plasma and urine. Ann. Clin. Biochem., 24, 552.

Strickland, R. A., Hill, T. R. \& Zagola, G. P. (1989a). Bedside analysis of arterial blood gases and 
electrolytes during and after cardiac surgery. J. Clin. Anesthesiol., 1, 248.

Strickland, R. A. Hill, T. R. \& Zagola, G. P. (1989b). Bedside blood gas and electrolyte monitoring in critically ill patients. Crit. Care Med., 17, 920.

Thoma, A. P., Viviani-Nauer, A., Arvanitis, S., Morf, W. E. \& Simon, W. (1977). Mechanisms of neutral carrier mediated ion transport through ionselective bulk membranes. Anal. Chem., 49, 1567.

Tierney, M. J. \& Martin, C. R. (1990). New electrorelease systems based on microporous membranes. J. Electrochem. Soc., 137, 3789.

Van Der Wal, P. D., Skowronska-Ptasinska, M., Van Den Berg, A., Bergveld, P., Sudholter, E. J. R. \& Reinhoudt, D. N. (1990). New membrane materials for potassium-selective ion-selective field-effect transistors. Anal. Chim. Acta, 231, 41.
Walter, B. (1983). Dry reagent chemistries in clinical analysis. Anal. Chem., 55, 498A.

Wolfbeis, O. S. (1991). Optical sensing based on analyte recognition by enzymes, carriers and molecular interactions. Anal. Chim. Acta, 250, 181.

Wuthier, U., Pham, H. V., Zünd, R., Welti, D., Funck, R. J. J., Bezegh, A., Ammann, D.. Pretsch, E. \& Simon, W. (1984). Tin organic compounds as neutral carriers for anion selective electrodes. Anal. Chem., 56, 535.

Yim, H. S. \& Meyerhoff, M. E. (1992). Reversible potentiometric oxygen sensors based on polymeric and metallic film electrodes. Anal. Chem., 64, 1777.

Yim, H. S., Cha, G. S. \& Meyerhoff, M. E. (1990). Differential ion-selective membrane electrodebased potentiometric gas-sensing cells with enhanced gas sensitivity. Anal. Chim. Acta, 237, 115. 